\title{
Inhibition of Premixed Carbon Monoxide-Hydrogen- Oxygen-Nitrogen Flames by Iron Pentacarbonyl
}

Marc D. Rumminger and Gregory T. Linteris

Building and Fire Research Laboratory

Gaithersburg, Maryland 20899

\section{NGT}

United States Department of Commerce

Technology Administration

National Institute of Standards and Technology 


\section{Inhibition of Premixed Carbon Monoxide-Hydrogen- Oxygen-Nitrogen Flames by Iron Pentacarbonyl}

Marc D. Rumminger and Gregory T. Linteris

October, 1999

Building and Fire Research Laboratory

National Institute of Standards and Technology

Gaithersburg, MD 20899

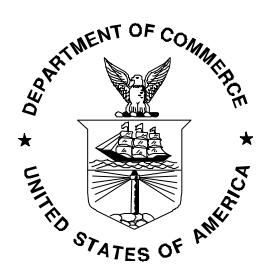

U.S. Department of Commerce

William M. Daley, Secretary

Technology Administration

Gary Bachula, Acting Under Secretary for Technology

National Institute of Standards and Technology

Raymond G. Kammer, Director 


\title{
INHIBITION OF PREMIXED CARBON MONOXIDE-HYDROGEN-OXYGEN- NITROGEN FLAMES BY IRON PENTACARBONYL ${ }^{+}$
}

\author{
Marc D. Rumminger‡ and Gregory T. Linteris§ \\ Building and Fire Research Laboratory \\ National Institute of Standards and Technology, Gaithersburg MD 20899-8651, USA \\ (marc.rumminger@nist.gov, linteris@ist.gov)
}

\begin{abstract}
This paper presents measurements of the burning velocity of premixed $\mathrm{CO}-\mathrm{H}_{2}-\mathrm{O}_{2}-\mathrm{N}_{2}$ flames with and without the inhibitor $\mathrm{Fe}(\mathrm{CO})_{5}$ over a range of initial $\mathrm{H}_{2}$ and $\mathrm{O}_{2}$ mole fractions. A numerical model is used to simulate the flame inhibition using a gas-phase chemical mechanism. For the uninhibited flames, predictions of burning velocity are excellent and for the inhibited flames, the qualitative agreement is good. The agreement depends strongly on the rate of the $\mathrm{CO}+\mathrm{OH} \leftrightarrow \mathrm{CO}_{2} \mathrm{H}$ reaction and the rates of several key iron reactions in catalytic $\mathrm{H}$ - and $\mathrm{O}$-atom scavenging cycles. Most of the chemical inhibition occurs through a catalytic cycle that converts $\mathrm{O}$ atoms into $\mathrm{O}_{2}$ molecules. This $\mathrm{O}$-atom cycle is not important in methane flames. The $\mathrm{H}$-atom cycle that causes most of the radical scavenging in the methane flames is also active in $\mathrm{CO}-\mathrm{H}_{2}$ flames, but is of secondary importance. To vary the role of the $\mathrm{H}$ - and $\mathrm{O}$-atom radical pools, the experiments and calculations are performed over a range of oxygen and hydrogen mole fraction. The degree of inhibition is shown to be related to the fraction of the net $\mathrm{H}$ - and $\mathrm{O}$-atom destruction through the iron species catalytic cycles. The Oatom cycle saturates at a relatively low inhibitor mole fraction ( $-100 \mathrm{ppm})$, while the $\mathrm{H}$ atom cycle saturates at a much higher inhibitor mole fraction ( $-400 \mathrm{ppm})$. The calculations reinforce the previously suggested idea that catalytic cycle saturation effects may limit the achievable degree of chemical inhibition.
\end{abstract}

\section{INTRODUCTION}

The production of the effective and widely-used fire suppressant $\mathrm{CF}_{3} \mathrm{Br}$ and other related compounds has been banned due to their contribution to ozone depletion. Currently, there exists no replacement fire suppressant with all of the desirable

\footnotetext{
† Official contribution of the National Institute of Standards and Technology, not subject to copyright in the United States.

₹ National Research Council/ NIST postdoctoral fellow

$\S$ Corresponding author
} 
properties of $\mathrm{CF}_{3} \mathrm{Br}$, and the search for alternative compounds has intensified. It is well-established that some metallic compounds are very powerful flame inhibitors [15]. The compound iron pentacarbonyl $\left(\mathrm{Fe}(\mathrm{CO})_{5}\right)$ has been found to be up to two orders of magnitude more effective than bromine-containing compounds at reducing the burning velocity of premixed hydrocarbon-air flames [1,6]. Although $\mathrm{Fe}(\mathrm{CO})_{5}$ is toxic and flammable, understanding its inhibition mechanism could provide insight into the behavior of other highly effective agents and aid in the development of new non-toxic agents.

In recent years, several detailed studies of $\mathrm{Fe}(\mathrm{CO})_{5}$ have been undertaken. Reinelt and Linteris [7] studied the flame inhibition effect of iron pentacarbonyl in methane-oxygen-nitrogen mixtures by measuring the burning velocity of premixed flames and the extinction strain rate of counterflow diffusion flames. The experiments showed that for small amounts of $\mathrm{Fe}(\mathrm{CO})_{5}$ the effect was roughly linear, but above a certain loading the effect was nearly independent of the $\mathrm{Fe}(\mathrm{CO})_{5}$ concentration. The authors postulated that the decreasing inhibition was due to loss of active gas-phase species through condensation. Rumminger et al. [8] developed a chemical mechanism for $\mathrm{Fe}(\mathrm{CO})_{5}$ inhibition of methane-oxygen-nitrogen flames, and through numerical simulations concluded that the inhibition occurs primarily through gas-phase chemistry. Flame simulations using the chemical mechanism in Ref. [8] showed promising agreement between model and experiment. The mechanism successfully predicted the trends for various equivalence ratios and oxygen mole fractions; however, the authors had increased the rates of several key reactions* (within experimental uncertainty) to improve quantitative agreement, and consequently recommended additional testing and refinement of the mechanism.

In the present paper we examine the effect of $\mathrm{Fe}(\mathrm{CO})_{5}$ in $\mathrm{CO}-\mathrm{H}_{2}-\mathrm{O}_{2}-\mathrm{N}_{2}$ flames, which have a different radical pool than the methane flames of previous studies. Calculations of uninhibited premixed flame structure indicate that the peak mole fraction of $\mathrm{O}$ atom is four times higher in stoichiometric $\mathrm{CO}-\mathrm{H}_{2}$-air flames (containing between 0.2 and $1.0 \% \mathrm{H}_{2}$ ) than a stoichiometric $\mathrm{CH}_{4}$-air flame, while the concentrations of $\mathrm{H}$-atom and $\mathrm{OH}$ are between 1.5 and 7 times lower. These differences permit examination of the effect of radical pool composition on inhibition. Since previous calculations [8] $]^{\text {th }}$ have shown that inhibition in methane flames occurs primarily from radical recombination cycles involving $\mathrm{H}$ atoms, it is of interest to determine if other mechanisms are important in flames with reduced $\mathrm{H}$-atom mole fraction. In $\mathrm{CO}$ flames the $\mathrm{H}$-atom mole fraction can be adjusted by varying the amount of $\mathrm{H}_{2}$ in the reactant mixture. Finally, the numerical calculations in methane-air flames indicated that above a certain loading chemical inhibitors can lose their effectiveness because the radical

\footnotetext{
** The reactions and increased rates were $\mathrm{FeO}+\mathrm{H}_{2} \mathrm{O} \leftrightarrow \mathrm{Fe}(\mathrm{OH})_{2}\left(\mathrm{k}_{f}=1.62 \mathrm{E}+13\right.$, increased by $\left.3 \mathrm{X}\right)$, $\mathrm{FeOH}+\mathrm{H} \leftrightarrow \mathrm{FeO}+\mathrm{H}_{2}\left(\mathrm{k}_{\mathrm{f}}=1.50 \mathrm{E}+14 \exp (-805 / \mathrm{T})\right.$, increased by $\left.5 \mathrm{X}\right), \mathrm{Fe}(\mathrm{OH})_{2}+\mathrm{H} \leftrightarrow \mathrm{FeOH}+\mathrm{H}_{2} \mathrm{O}\left(\mathrm{k}_{\mathrm{f}}=\right.$ $1.98 \mathrm{E}+14 \exp (-302 / \mathrm{T})$, increased by 3X).

t† To avoid excessive repetition, references to previous cal culations of $\mathrm{Fe}(\mathrm{CO})_{5}$-inhibited methane flames refer to Ref. [8] unless otherwise noted.
} 
pool has already been lowered to equilibrium levels. By varying the radical pool size, CO flames can be used to investigate whether the observed saturation in iron pentacarbonyl's effectiveness is due to condensation or radical pool depletion.

The oxidation mechanism of CO has fewer reactions than those of hydrocarbon fuels, allowing easier isolation of the important inhibition reactions. For this reason, many researchers have used CO flames in studies of halogen inhibition [9-16]. The simplicity of the $\mathrm{CO}$ system has additional significance in the present work. In previous studies with methane flames, the rates of key inhibition reactions suggested by Jensen and Jones [17] were increased in order to accurately match the observed burning velocity reductions. It is of interest here to determine if the faster rates are necessary for modeling moist $\mathrm{CO}$ flames-which are chemically much closer to the rich $\mathrm{H}_{2}-\mathrm{O}_{2}$ flames used by Jensen and Jones (reactions of iron-containing species with hydrocarbons are not presently included in the mechanism). Finally, carbon monoxide flames are relevant to fire research since $\mathrm{CO}$ is a dominant intermediate species in hydrocarbon flames and its oxidation is often the rate-limiting step in product formation.

The approach in the present research is to determine the effect of $\mathrm{Fe}(\mathrm{CO})_{5}$ on the overall reaction rate of premixed flames. The burning velocity of a premixed laminar flame is a relative measure of the overall reaction rate. Since this reaction rate is a fundamental parameter affecting the stabilization and fuel consumption rate of fires, the extent to which it is influenced by the agent is a first measure of the agent's potential as a fire suppressant. Although suppression tests on full-scale fires will be required to assure the effectiveness of any agent, laboratory burners have several important benefits. Their simplicity allows rapid assessment of inhibitor performance in many flame conditions and at various concentrations, and the flames are highly reproducible and stable. Premixed laminar flames can be nearly adiabatic in the laboratory, and are easily modeled with existing computer programs, allowing straightforward interpretation of the effect of the inhibitor. By using detailed chemical kinetic mechanisms together with full transport calculations, the chemical species profiles throughout the flames are calculated. These results provide great insight into both the chemical and physical mechanisms of the inhibitor. Also, in a well-designed laboratory burner, there is little ambiguity about how much agent reaches the flame. Although techniques such as detailed flame structure measurements provide valuable information about the chemical species at each location in the flame for one particular condition, burning velocity and extinction strain rate measurements have the advantage of allowing rapid testing of the effect of the inhibitor over a wider range of conditions.

Our study of flame inhibition is intended to provide insights into flame suppression. Although the processes have different end points (weakening the flame vs. extinguishing it), the underlying mechanism is similar: the agent reduces the overall reaction rate of the fuel-air mixture. Inhibition can be viewed as an early stage of suppression in which the inhibitor weakens the flame, making it more vulnerable to extinction by external factors such as heat loss or fluid-mechanical instability. Inhibition-and eventually suppression-occurs as the agent reduces the rate of heat 
release of the flame. For chemically-acting agents, the agent interferes with the reactions which consume the fuel and intermediates. Hence, we can study the effect of small agent concentrations on flame chemistry and build chemical kinetic models which describe the effect of the agent on the combustion reactions. By using laboratory-scale premixed and diffusion flames that are amenable to modeling, we can validate the chemical kinetic model and gain insight into which processes are most important. Later, we can continue to construct and refine the mechanism for higher inhibitor concentrations and for flames and fuels which are more representative of fires. Finally, an understanding of the modes of action of effective agents such as $\mathrm{Fe}(\mathrm{CO})_{5}$ can lead researchers to chemicals that have similar favorable properties, while avoiding characteristics such as diminishing effectiveness at high concentration.

In addition to the flame inhibition experiments and modeling, we present measurements of the burning velocity of uninhibited $\mathrm{CO}-\mathrm{H}_{2}-\mathrm{O}_{2}-\mathrm{N}_{2}$ flames with varying amounts of $\mathrm{H}_{2}$, and compare the measurements with calculations. Although there are numerous measurements of $\mathrm{CO}$ flame speed in the literature [9,18-21], there is a lack of data for near-stoichiometric $\mathrm{CO}-\mathrm{H}_{2}-\mathrm{O}_{2}-\mathrm{N}_{2}$ flames with $\mathrm{H}_{2}$ mole fractions between $1.50 \cdot 10^{-4}$ and $2.0 \cdot 10^{2}$.

In the remainder of the paper, we describe the experimental technique, the numerical calculation procedure, and the results for uninhibited and inhibited $\mathrm{CO}-\mathrm{H}_{2-}$ $\mathrm{O}_{2}-\mathrm{N}_{2}$ flames. We interpret the chemical kinetics of the inhibiting iron species in $\mathrm{CO}$ flames, comparing them with results for $\mathrm{CH}_{4}$ flames, and analyze how changing oxygen or hydrogen content affects the flame inhibition.

\section{EXPERIMENTAL}

\section{Premixed Flame System}

A Mache-Hebra nozzle burner (inner diameter $1.02 \pm 0.005 \mathrm{~cm}$ ) [22] with a schlieren imaging system [23], is used to measure the average burning velocity with the total area method [24]. The burner produces straight-sided schlieren and visible images which are very closely parallel. Gas flows are measured with digitally-controlled mass flow controllers (Sierra Model $860^{\ddagger}$ ) with a quoted repeatability of $0.2 \%$ and accuracy of $1 \%$ of full-scale flow, which have been calibrated with bubble (Gillian Gilibrator) and dry (A merican Meter Co. DTM-200A) flow meters so that their accuracy is $1 \%$ of indicated flow. The fuel gas is carbon monoxide (Matheson UHP, $99.9 \% \mathrm{CO}$, with the sum of $\mathrm{CH}_{4}$ and $\mathrm{H}_{2} \mathrm{O}<10 \mathrm{ppm}$ ) and hydrogen (Matheson UHP, $99.999 \% \mathrm{H}_{2}$, with sum of $\mathrm{N}_{2}, \mathrm{O}_{2} \mathrm{CO}_{2}, \mathrm{CO}, \mathrm{Ar}, \mathrm{CH}_{4}$, and $\mathrm{H}_{2} \mathrm{O}<10 \mathrm{ppm}$ ); the oxidizer stream consists of nitrogen (boil-off from liquid $\mathrm{N}_{2}$ ) and oxygen (MG Industries, $\mathrm{H}_{2} \mathrm{O}<50 \mathrm{ppm}$, total hydrocarbons $<5$ ppm). The experimental arrangement has been described in detail

\# Certain commercial equipment, instruments, or materials are identified in this paper to adequately specify the procedure. Such identification does not imply recommendation or endorsement by the National Institute of Standards and Technology, nor does it imply that the materials or equipment are necessarily the best available for the intended use. 
previously [25] and the optical and image processing systems have been refined as described below.

Inhibitor is added to the flame by diverting part of the nitrogen stream to a twostage saturator maintained in an ice bath at $0^{\circ} \mathrm{C}$. The diverted gas (less than $8 \%$ of the total flow) bubbles through liquid $\mathrm{Fe}(\mathrm{CO})_{5}$ before returning to the main nitrogen flow, and is assumed to be saturated with $\mathrm{Fe}(\mathrm{CO})_{5}$ vapor. Although the saturator is the same as used previously, the assumption of saturation has been verified by flowing the $\mathrm{Fe}(\mathrm{CO})_{5}$-laden gases into a condensation coil immersed in a $-60^{\circ} \mathrm{C}$ alcohol bath. After a specified elapsed time, the ends of the coil were capped and the weight gain of the coil (i.e., the amount of $\mathrm{Fe}(\mathrm{CO})_{5}$ ) was measured. After performing the condensation experiment for several carrier-gas flow rates, a linear fit of the data was generated to quantify the dependence of $\mathrm{Fe}(\mathrm{CO})_{5}$ concentration on carrier-gas flow rate. The experimental results and theoretical prediction based on carrier-gas saturation were within $5 \%$ of each other across a wide range of flow rates.

The schlieren image of the flame is used to represent the flame surface. An optical system (a white-light source with a vertical slit at its exit, lenses, a vertical band, and filters) generates the schlieren image of the flame for capture by a $776 \times 512$ pixel CID array (Cidtec CID3710D). The image is digitized by a $640 \times 480$ pixel framegrabber board (Data Translation 3155) in a Pentium-II computer. The images are acquired and written to disk using the free UTHSCSA ImageT ool program [26]. For each flame condition, 10 images are collected at a rate of one per second. The flame area is determined (assuming axial symmetry) using custom image-processing software. Finally, the burning velocity is calculated by dividing the volumetric flow rate (corrected to 1 atmosphere and $298 \mathrm{~K}$ ) by the average flame area for the $10 \mathrm{images}$.

In these experiments, the low rate of heat loss to the burner, the low strain rate, and the low curvature facilitate comparisons of the burning velocity with those predicted by one-dimensional numerical calculations. Although the burning velocity in Bunsen-type flames is known to vary at the tip and base of the flame and is influenced by curvature and stretch [24], these effects are most important over a small portion of the flame. In order to minimize the influence of these effects on interpretation of the action of the chemical inhibitor, we present the burning velocity as a normalized parameter: the burning velocity of the inhibited flame divided by the burning velocity of the uninhibited flame at the sameflow conditions (the burning velocities used for the normalizations are listed in Table 1).

\section{Uncertainty Analysis}

The uncertainty analysis consists of calculation of individual uncertainty components and root mean square summation of components [27]. Calculation of the individual uncertain components is accomplished analytically for simple expressions (e.g., equivalence ratio), and through use of a 'jitter program' [28] for more complex expressions (e.g., $\mathrm{Fe}(\mathrm{CO})_{5}$ mole fraction). The jitter program sequentially varies the input data and computes the resulting contribution to the uncertainty for each output variable. All uncertainties are reported as expanded uncertainties: $X \pm U$, where $U$ is $\mathrm{ku}_{c}$, and is determined from a combined standard uncertainty (estimated standard 
deviation) $u_{c}$, and a coverage factor $k=2$ (level of confidence approximately 95\%). Likewise, when reported, the relative uncertainty is $\mathrm{U} / \mathrm{X} \cdot 100 \%$, or $\mathrm{ku}_{\mathrm{c}} / \mathrm{X} \cdot 100 \%$. The primary sources of uncertainty in the average burning velocity measurement are 1 ) accuracy of the flow controllers, 2) measurement of ambient pressure and temperature, 3) determination of the flame area, 4) the effect of flame base location on flame area, 5) the location of the schlieren image relative to the cold gas boundary.

The relative uncertainty in total flow rate is $0.7 \%$, which includes the uncertainty of the flow controllers and uncertainty in the measurements of ambient temperature and pressure. The uncertainty in flame area is affected by uncertainty in the pixel to $\mathrm{mm}$ conversion (1\%); the uncertainty in the distance between the flame base and the burner surface; and image-to-image variability (from $0.5 \%$ to $6 \%$, with higher variability at higher flow rates).

The distance between the flame base and the burner surface is one of the inputs to the image-processing software. For a given fuel and oxidizer, a single separation distance is acceptable since extensive examination of the flame images shows it to be constant even for different inhibitor loading or mixture stoichiometry. Additionally, it has been shown that the distance between the flame base and burner base is nearly constant for Bunsen-type hydrocarbon flames with a uniform velocity profile at the burner exit for $\phi$ between 0.8 and 1.3 [29]. When the $\mathrm{Fe}(\mathrm{CO})_{5}$ loading is high, though, the location of the flame base can change as iron oxide powder collects on the burner rim. We have measured the buildup and accounted for it when specifying the flameto-burner separation distance. (Note that the measurements of absolute burning velocity of uninhibited flames that we report here, Table $1 \&$ Table 2 below, were made using clean, deposit-free burner rims.)

From analysis of multiple flame images and calculation of flame area using varying flame base locations, we estimate that the uncertainty of the flame base location is $0.1 \mathrm{~mm}$, and the resulting uncertainty in the flame area is about $2 \%$. The selection of flame base location has a negligible effect on normalized burning velocity, as the normalization eliminates the error in flame base selection. Some uncertainty results from variations in heat loss at each test condition, but since we maintain a constant flame height of $13 \mathrm{~mm}$ by adjusting the total flow rate, this term is small for absolute flame speed measurements, and negligible when the burning velocity is normalized. In summation, without consideration of the schlieren image position, the relative uncertainty for burning velocity measurements ranges between $3 \%$ and $6.5 \%$, and between $1 \%$ and $4.5 \%$ for normalized burning velocity. In general, uncertainty increases with increasing burning velocity. The tables of burning velocity assign uncertainty to each measurement of uninhibited burning velocity.

Uncertainty about the location of the schlieren image in the flame contributes additional uncertainty to the absolute burning velocity measurement. Traditionally, the burning velocity of the flame is the flow velocity of the unburned reactants; however, since the schlieren image corresponds to a surface with a temperature above that of the unburned gas [24], use of the schlieren image as the flame area can lead to an underestimation of the burning velocity [30]. Previous researchers [24,30,31] have attempted to adjust the flame area to the $298 \mathrm{~K}$ isotherm $\left(T_{298}\right)$, although this generally 
requires knowledge of the 2-D temperature field in the flame. We do not make such corrections in this paper, and note that it has not yet been done using experimental (rather than calculated) data from a flame.

The uncertainties in the equivalence ratio, oxygen mole fraction and hydrogen content are related to the accuracy of the flow controllers. The expanded relative uncertainties for the these quantities are as follows: $1.4 \%$ for equivalence ratio; $1.1 \%$ for oxygen mole fraction measurement; and $1.2 \%$ for hydrogen mole fraction in the reactants.The amount of hydrogen contamination of the bottled gases, based on the manufacturer's analysis, is estimated to be less than 75 ppm.

The uncertainty of $\mathrm{Fe}(\mathrm{CO})_{5}$ concentration is calculated assuming that the concentration depends on the vapor pressure of $\mathrm{Fe}(\mathrm{CO})_{5}$, laboratory temperature, laboratory pressure, and gas flow rate. The correlation for the vapor pressure of $\mathrm{Fe}(\mathrm{CO})_{5}$ is from Gilbert and Sulzmann [32], but the paper does not provide uncertainty for the correlation. Nonetheless, uncertainty in the bath temperature, the ambient pressure and the carrier gas flow rate results in an uncertainty of $\mathrm{Fe}(\mathrm{CO})_{5}$ mole fraction of approximately $\pm 6.5 \%$.

\section{NUMERICAL MODEL}

One-dimensional freely-propagating premixed flames are simulated using the Sandia flame code Premix [33], the Chemkin subroutines [34], and the transport property subroutines [35]. For all of the calculations the absolute tolerance is $10^{-14}$, the relative tolerance is $10^{-9}$, GRAD is 0.20 , and CURV is 0.35 . Thermal diffusion (Soret effect) is included in the calculations. Solutions typically contain between 85 and 130 grid points. The initial temperature is $298 \mathrm{~K}$ and the pressure is one atmosphere. The kinetic mechanism and thermodynamic data of Yetter et al. [36] (13 species and 37 chemical reactions) serve as a basis for describing moist carbon monoxide oxidation. Note that we use the modified Arrhenius rate for $\mathrm{CO}+\mathrm{OH} \leftrightarrow \mathrm{CO}_{2}+\mathrm{H}$ from Baulch et al. [37] because numerical calculations indicated that most of the $\mathrm{CO}$ oxidation was occurring below $2000 \mathrm{~K}$ (temperature above which a different rate expression was recommended [36]). Iron pentacarbonyl is added to the unburned $\mathrm{CO}-\mathrm{H}_{2}-\mathrm{O}_{2}-\mathrm{N}_{2}$ mixture at mole fractions of up to $500 \mathrm{ppm}$. The chemical mechanism for $\mathrm{Fe}(\mathrm{CO})_{5}$ inhibition of flames (12 species and 55 reactions) and necessary thermodynamic and transport data are compiled from a variety of sources as described in Ref. [8]. It should be emphasized that the reaction mechanism used for the present calculations should be considered only as a starting point. Numerous changes to both the rates and the reactions incorporated may be made once a variety of experimental and theoretical data are available for testing the mechanism. 


\section{RESULTS AND DISCUSSION}

\section{Uninhibited flames}

Figure 1 shows the measured burning velocities for $\mathrm{CO}-\mathrm{H}_{2}$-air flames with varying amounts of hydrogen (for the reader's convenience, the data are also presented in tabular form in Table 2). We were not able to obtain a steady flame for hydrogen mole fractions $\left(\mathrm{X}_{\mathrm{H}_{2}}\right)$ below 0.0024 or above 0.014 . If extrapolated to hydrogen-free conditions, our measurements would agree reasonably well with the measurements of Palmer and Seery [9], who used the cone frustum method (reported measurement uncertainty of $\pm 10 \%$ ) to measure the burning velocity of CO-air flames with $45-150 \mathrm{ppm}$ of $\mathrm{H}_{2}$.

Figure 1 also shows the calculated burning velocity using the mechanism from Ref. [36] with several different sets of rate constants for $\mathrm{CO}+\mathrm{OH} \rightarrow \mathrm{CO}_{2}+\mathrm{H}$ [37-40]. 
Table 3 lists calculated forward rate constants for each formulation at several temperatures. The 1992 rate expression of Baulch et al. [39] yields a burning velocity about $20 \%$ higher than the experiments, while the remaining three rate expressions predict values less than $10 \%$ lower than the experiments. Since there is a relatively large uncertainty in the rate of $\mathrm{CO}+\mathrm{OH}$ near $2000 \mathrm{~K}$ [41], adjustment of this rate to match the present data seems unwarranted.

Examination of the numerical results shows that the $\mathrm{CO}+\mathrm{OH}$ reaction is important even at very low hydrogen concentration. At $\mathrm{X}_{\mathrm{H}_{2}}=0.001,70 \%$ of the $\mathrm{CO}$ oxidation proceeds through $\mathrm{CO}+\mathrm{OH}$, while $28 \%$ of the $\mathrm{CO}$ oxidation proceeds through $\mathrm{CO}+\mathrm{O}+\mathrm{M}$. At $\mathrm{X}_{\mathrm{H}_{2}}=0.015$ the split is $88 \%$ through $\mathrm{CO}+\mathrm{OH}$ and $10 \%$ through $\mathrm{CO}+\mathrm{O}+\mathrm{M}$.

\section{Inhibited Flames}

\section{Effect of $\mathrm{O}_{2}$ M ole Fraction}

Figure 2 presents measurements (symbols) and calculations (lines) of the burning velocity of $\mathrm{Fe}(\mathrm{CO})_{5}$-inhibited $\mathrm{CO}-\mathrm{H}_{2}-\mathrm{O}_{2}-\mathrm{N}_{2}$ flames with varying amounts of oxygen. As previously seen for $\mathrm{CH}_{4}$-air flames inhibited by $\mathrm{Fe}(\mathrm{CO})_{5}$, inhibition is strongest in the flames with the lowest $\mathrm{X}_{\mathrm{O}_{2,0 x}} \quad\left(\mathrm{X}_{\mathrm{O}_{2}, 0 \mathrm{x}}\right.$ refers to the oxygen mole fraction in the oxidizer prior to mixing with the fuel). The experimental results show that inhibition is proportional to inhibitor concentration at low inhibitor mole fraction $\left(X_{\text {in }}\right)$, but after a certain concentration, additional $\mathrm{Fe}(\mathrm{CO})_{5}$ has little effect on the burning velocity. A plausible (but untested) explanation is that particle formation removes the inhibiting species at high inhibitor loading [7]. The experimental results in Figure 2 support this suggestion: as the flame temperature increases, the leveling-off point shifts to higher $\mathrm{Fe}(\mathrm{CO})_{5}$ mole fraction.

Changing the oxygen mole fraction of the uninhibited $\mathrm{CO}$ flames changes several features which may affect the burning velocity reduction caused by added $\mathrm{Fe}(\mathrm{CO})_{5}$. Table 4 lists the peak temperature and peak mole fraction of $\mathrm{O}, \mathrm{H}$, and $\mathrm{OH}$ in uninhibited flames with $\mathrm{X}_{\mathrm{O}_{2}, 0 \mathrm{x}}$ equal to $0.183,0.21$, and 0.24 . Raising the oxygen mole fraction over this range increases the final temperature by $209 \mathrm{~K}$ and the peak radical mole fractions by $30 \%$ to $60 \%$. Although several variables are changing simultaneously, it is reasonable to expect the hotter flames, with their larger radical pool, to be affected less by a fixed quantity of $\mathrm{Fe}(\mathrm{CO})_{5}$, yielding the smaller slope in Figure 2. (A detailed analysis of the effect of $\mathrm{X}_{\mathrm{O}_{2}, \mathrm{x}}$ is undertaken later in this paper.)

The calculated normalized burning velocities (shown by the lines in Figure 2) reproduce the trend of greater inhibition at lower $X_{0_{2}, 0 x}$ for low $X_{i n}$, and predict a reduced marginal effect as more inhibitor is added. At low values of $X_{i n}$, the slopes of the predicted normalized burning velocity curves are reasonably close to the measured slopes, but above about 100 ppm the measured and calculated normalized burning velocities diverge, with the model failing to reproduce the leveling off and overpredicting the inhibition effect. Nonetheless, we can use the numerical results at low inhibitor mole fraction to understand the reasons for the greater inhibition at lower $\mathrm{X}_{\mathrm{O}_{2}, 0 \mathrm{x}}$, as well as other features. Further, results at higher values of $\mathrm{X}_{\text {in }}$ can be used to 
investigate the relevant gas-phase chemistry predicted by the model if there was not a loss of the active species to a condensed phase.

The information obtained from flame speed measurements is global, and many reactions in the mechanism can affect the results. Nonetheless, a comparison of the measured and predicted burning velocities together with investigation of the numerical results can be used to identify key reactions for further investigation. In previous work with methane flames, the rates of the dominant inhibition reactions (those in the $\mathrm{H}$ atom cycle recommended by Jensen and Jones [17]) were increased (within experimental uncertainty) to better predict the experimental results. In Figure 2, the model shows slightly more inhibition for $\mathrm{X}_{\mathrm{O}_{2}, \mathrm{x}}=0.24$ than the experiments. While it is tempting to use the present data to move the rates of the $\mathrm{H}$-atom cycle back in the direction of the original recommendations [17], it is premature to do so. The excessive inhibition only occurs for one case; also, the effect of reaction rates in the fuel oxidation mechanism (exclusive of the inhibition mechanism) must be considered, as will be described below. Based on these considerations, we use the increased rates for the $\mathrm{H}$ atom cycle reactions for the analyses in the present paper.

As described in a preceding section and Figure 1, for uninhibited CO flames, the rate of the reaction $\mathrm{CO}+\mathrm{OH}$ has a large effect on the burning velocity predicted by the numerical calculation. For inhibited flames, the rates of the key inhibition steps obviously have a large effect on model performance. However, the rate selected for the $\mathrm{CO}+\mathrm{OH}$ reaction also affects the degree of predicted inhibition by $\mathrm{Fe}(\mathrm{CO})_{5}$. Figure 3 shows the combined effect of differing rates for the $\mathrm{CO}+\mathrm{OH}$ reaction and for the reactions in the $\mathrm{H}$-atom cycle [8]. The measured and predicted normalized burning velocities as a function of the mole fraction of $\mathrm{Fe}(\mathrm{CO})_{5}$ are shown for two values of the $\mathrm{CO}+\mathrm{OH}$ rate and for the fast and slow rates for the $\mathrm{H}$-atom recombination cycle. As the figure shows, the selection of the appropriate rates for the inhibition reactions depends upon selection of the $\mathrm{CO}+\mathrm{OH}$ rate.

For the remainder of this paper, we use the 1973 Baulch et al. [37] $\mathrm{CO}+\mathrm{OH}$ rate recommended by Yetter et al. [36] and the faster rates for the $\mathrm{H}$-atom cycle reactions from Ref. [8]. As illustrated in the NIST Chemical Kinetics Database [41], there is large uncertainty in the rate of $\mathrm{CO}+\mathrm{OH}$ near $1800 \mathrm{~K}$. Although the rate of $\mathrm{Yu}$ et al. [38] provides better agreement with our experimental data (Figure 1), we retain the 1973 Baulch et al. [37] rate since it has been extensively tested against a variety of experimental data from flames, flow reactors, and shock tubes [36]. For the inhibition reactions, the premixed methane flame results suggest use of the faster rates for the $\mathrm{H}$ atom cycle. In Figure 3, considering only the region of low $X_{\text {in, }}$, the results are ambiguous, although with the two rates for $\mathrm{CO}+\mathrm{OH}$, the faster rates for the cycle (solid lines) bracket the experimental data, while the slower rates for the cycle (dotted lines) lie predominantly outside the data. Also, the recent measurements of Rollason and Plane [42] for the reaction $\mathrm{FeO}+\mathrm{H}_{2} \mathrm{O}+\mathrm{He}\left(\mathrm{N}_{2}\right) \leftrightarrow \mathrm{Fe}(\mathrm{OH})_{2}+\mathrm{He}\left(\mathrm{N}_{2}\right)$, which is part of the $\mathrm{H}$ atom cycle, argue for a rate even higher than that suggested in Ref. [8]. N ote that while the absolute magnitude of the predicted inhibition is affected by the rates 
selected for the $\mathrm{H}$-atom cycle, the qualitative behavior is not, and the conclusions of this paper are unaffected by these rates.

\section{Catalytic Inhibition Cycles}

In previous research on bromine-containing species [43,44], conversion of radicals (e.g., $\mathrm{H}$ ) into less reactive species (e.g., $\mathrm{H}_{2}$ ) has been found to be the dominant mode of action for chemical inhibitors and suppressants. A similar $\mathrm{H}$-atom catalytic cycle involving iron oxide and hydroxide intermediates has been found to be important in $\mathrm{CH}_{4}-\mathrm{O}_{2}-\mathrm{N}_{2}$ flames inhibited by $\mathrm{Fe}(\mathrm{CO})_{5}$ [8]. Reaction pathway and sensitivity analyses for the inhibited $\mathrm{CO}$ flames reveals that the $\mathrm{H}$-atom catalytic cycle is active. $\mathrm{A}$ new finding, however, is that there is an additional catalytic cycle which scavenges $O$ atoms and which is much more important than the $\mathrm{H}$-atom cycle for $\mathrm{CO}$ flames. The appearance of $\mathrm{O}$-atom scavenging is consistent with the high peak $\mathrm{O}$-atom mole fraction of the present flames as compared to $\mathrm{H}$ or $\mathrm{OH}$ (see Table 5), and the finding that O-atom trapping is important for fluorinated-species inhibition of CO flames [16]. Recent computations of the thermochemistry of iron compounds at flame conditions support the possibility of multiple radical recombination cycles [45]. O-atom recombination by iron compounds has been reported previously [46] for flow tube experiments in which $\mathrm{Fe}(\mathrm{CO})_{5}$ was added to the reactant gases. Removal of O-atom by $\mathrm{CF}_{3} \mathrm{Br}$ in a flow tube has also been reported [47]. These previous studies, however, did not propose a catalytic cycle for $\mathrm{O}$-atom recombination.

The reactions that comprise the catalytic $\mathrm{O}$-atom scavenging cycle are

$$
\begin{aligned}
& \mathrm{Fe}+\mathrm{O}_{2}+\mathrm{M} \leftrightarrow \mathrm{FeO}+\mathrm{M} \\
& \mathrm{FeO}_{2}+\mathrm{O} \leftrightarrow \mathrm{FeO}+\mathrm{O}_{2} \\
& \mathrm{FeO}+\mathrm{O} \leftrightarrow \mathrm{Fe}+\mathrm{O}_{2} \\
& \hline \mathrm{O}+\mathrm{O} \leftrightarrow \mathrm{O}_{2} .
\end{aligned}
$$

The first and third reactions in the cycle have been studied in the laboratory. The rate for (R1) has been measured by several researchers [48,49], and the rate for (R3) has been measured by Fontijn et al. [50]. The rate for second reaction was estimated [8]; lowering its rate reduces the calculated inhibition and improves agreement with the present experiments.

The primary reaction pathways for iron species are shown in Figure 4, where both the $\mathrm{H}$ - and $\mathrm{O}$-atom catalytic cycles are illustrated. $\mathrm{Fe}(\mathrm{CO})_{5}$ decomposition occurs through several steps in which the CO ligands are sequentially removed (for simplicity, these steps are not shown in the figure), leaving $\mathrm{Fe}$. The Fe is converted first to $\mathrm{FeO}_{2}$ and then to $\mathrm{FeO}$. A portion of the $\mathrm{FeO}$ is converted back to $\mathrm{Fe}$, thus completing the Oatom cycle; the remainder of the $\mathrm{FeO}$ participates in the $\mathrm{H}$-atom cycle.

Although the reactions (R1)-(R3) were present in the inhibition mechanism, a significant contribution from the O-atom cycle was not found in the studies of $\mathrm{CH}_{4}-\mathrm{O}_{2}$ $\mathrm{N}_{2}$ flames. Instead, reactions (R1)-(R2) converted Fe to one of the species in the main 
inhibition cycle (FeO), and (R3) was a minor reaction. The authors found that most of the radical scavenging for methane flames occurs through the $\mathrm{H}$-atom catalytic cycle.

Part of the effect of the catalytic cycles illustrated in Figure 4 is a suppression of radical superequilibrium. Figure 5 shows the calculated $\mathrm{O}$-atom mole fraction as a function of position in stoichiometric CO-H $\mathrm{H}_{2}$-air flames with $\mathrm{X}_{\mathrm{H}_{2}}=0.01$ and various $\mathrm{X}_{\text {in }}$. As the inhibitor mole fraction increases, the peak mole fraction decreases; and perhaps more important, the amount of superequilibrium decreases, providing fewer radicals to support flame propagation. The $\mathrm{H}$-atom superequilibrium also decreases, partially through catalytic scavenging, and partially as a result of the fast $\mathrm{O}, \mathrm{H}$, and $\mathrm{OH}$ shuffle reactions.

Returning to the results in Figure 2, we examine why the inhibition decreases as $\mathrm{X}_{\mathrm{O}_{2}, 0 \mathrm{x}}$ increases using the technique of reaction flux analysis. From the numerical results, we calculate the reaction flux $F_{i, k}=\int_{t_{1}}^{t_{2}} v_{i k} q_{i}(R T / P) d t$ where $\mathrm{F}_{\mathrm{i}, \mathrm{k}}$ is the flux of species $k$ through reaction $i, v_{\mathrm{ik}}$ is the stoichiometric coefficient for species $\mathrm{k}$ in reaction $\mathrm{i}$, $q_{i}$ is the rate of progress of reaction $i, R$ is the universal gas constant, $T$ is the local gas temperature, $P$ is the pressure, and $t_{1}$ and $t_{2}$ are the time bounds of integration. The distance coordinate at the $j$-th grid point $\left(x_{j}\right)$ is converted to time via $\mathrm{t}_{\mathrm{j}}=\mathrm{t}_{\mathrm{j}-1}+\left(\mathrm{x}_{\mathrm{j}}-\mathrm{x}_{\mathrm{j}-1}\right) \rho / \dot{\mathrm{m}}^{\prime \prime}$, where $\rho$ is the gas density, $\dot{\mathrm{m}}^{\prime \prime}$ is the mass flow rate per unit area. The rate of progress $\mathrm{q}_{\mathrm{i}}$ is defined as $k_{f_{i}} \prod_{k=1}^{K}\left[X_{k}\right]^{\eta_{i k}}-k_{r_{i}} \prod_{k=1}^{K}\left[X_{k}\right]^{{ }_{i k}}$, where $\mathrm{k}_{\mathrm{f}_{\mathrm{i}}}$ and $\mathrm{k}_{\mathrm{r}_{\mathrm{i}}}$ are the forward and reverse rate constants of reaction $\left.\mathrm{i} ; \mathrm{X}_{\mathrm{k}}\right]$ is the molar concentration of species $k ; v_{i k}^{\prime}$ and $v_{i k}^{\prime \prime}$ are the forward and reverse stoichiometric coefficients for species $k$ in reaction $i$; and $K$ is the total number of species. The start of the integration $\left(t_{1}\right)$ is the cold boundary. The choice of $t_{2}$ is somewhat arbitrary, and we use the time of maximum mole fraction of species $\mathrm{k}$. Such a choice for analysis of radical consumption may seem counterintuitive given that most of the net consumption occurs after the peak mole fraction. However, the bulk of the chain-branching and inhibition reactions occur before the point of peak mole fraction, and thus we integrate over the region where the important flame propagation chemistry occurs. Calculations show that the qualitative relationships of the fluxes at different flame conditions are not sensitive to the values of $t_{2}$ as long as $t_{2}$ is at or after the peak mole fraction.

We measure the relative importance of the iron reactions by calculating the fractions of $\mathrm{H}$-atom and $\mathrm{O}$-atom consumption that occur through the most important iron reactions (the "fractional flux"). For the i-th reaction and the k-th species the fractional flux $f_{i, k}$ is calculated as $f_{i, k}=F_{i, k} / \sum_{n=1}^{N} F_{n, k}$, where $N$ is the number of reactions in the chemical mechanism. For the $\mathrm{H}$-atom, the following reactions are considered: $\mathrm{Fe}(\mathrm{OH})_{2}+\mathrm{H} \leftrightarrow \mathrm{FeOH}+\mathrm{H}_{2} \mathrm{O}, \mathrm{FeOH}+\mathrm{H} \leftrightarrow \mathrm{FeO}+\mathrm{H}_{2}$, and $\mathrm{FeO}+\mathrm{H}_{2} \mathrm{O} \leftrightarrow \mathrm{Fe}(\mathrm{OH})_{2}$. For the O-atom, the following reactions are considered: $\mathrm{Fe}_{2} \mathrm{O}_{2}(+\mathrm{M}) \leftrightarrow \mathrm{FeO}_{2}(+\mathrm{M})$, $\mathrm{FeO}_{2}+\mathrm{O} \leftrightarrow \mathrm{FeO}+\mathrm{O}_{2}, \mathrm{FeO}+\mathrm{O} \leftrightarrow \mathrm{Fe}+\mathrm{O}_{2}, \mathrm{FeOH}+\mathrm{O}+\mathrm{M} \leftrightarrow \mathrm{FeOOH}+\mathrm{M}$. These are the reactions in the cycles of Figure 4; previous modeling results and analysis using the graphical 
post-processor X senkplot [51] have shown them to be the most important inhibition reactions.

Figure 6 shows the fraction of $\mathrm{H}$-atom and $\mathrm{O}$-atom flux through the catalytic cycles for three different values of $X_{0_{2}, 0 x}$. At low $X_{i n}$, the fractional flux is inversely related to $X_{0_{2}, 0 x}$. As $X_{0_{2}, 0 x}$ decreases, stronger inhibition may be caused by the larger fraction of $\mathrm{H}$ atoms (and to a lesser extent, $\mathrm{O}$ atoms) scavenged through the catalytic cycles. The inhibition cycles essentially compete with the chain branching reactions, and hence reduce the overall reaction rate. While most of the inhibition appears to result from recombination of $\mathrm{O}$ atoms, the reaction flux results imply that the difference in behavior at low and high $\mathrm{X}_{\mathrm{O}_{2}, \mathrm{x}}$ is due to the increasing importance of the $\mathrm{H}$-atom cycle at low $\mathrm{X}_{\mathrm{O}_{2}, \mathrm{x} \text {. }}$

The diminished effectiveness of $\mathrm{Fe}(\mathrm{CO})_{5}$ at high $\mathrm{X}_{\text {in }}$ may be explained, in part, by the behavior illustrated in Figure 6. A bove $100-200 \mathrm{ppm}$ of $\mathrm{Fe}(\mathrm{CO})_{5}$, the O-atom cycle saturates. That is, increasing $X_{\text {in }}$ does not lead to a greater fraction of the radicals being recombined by the iron species. The $\mathrm{H}$-atom cycle saturates at values of $\mathrm{X}_{\text {in }}$ only slightly higher. The saturation explains why the calculated curves in Figure 2 have decreasing slopes as $X_{\text {in }}$ increases. It is of interest to note that inhibition caused by $\mathrm{Fe}(\mathrm{CO})_{5}$ diminishes more rapidly in $\mathrm{CO}$ flames than $\mathrm{CH}_{4}$ flames. Part of the reason may be due to the importance of the O-atom cycle for $\mathrm{CO}$ flames and the rapid saturation of this cycle relative to the $\mathrm{H}$-atom cycle. These explanations are obtained from the calculated results; while saturation might conceivably occur in the actual flames, it should be emphasized that the experiments show an even greater loss of effectiveness, and the modeling and experimental results do not agree well at higher values of $X_{i n}$. The discrepancy has been attributed to loss of inhibiting species through condensation [7].

The saturation of catalytic cycles again suggests the existence of limits to chemical inhibition, as was previously shown for an idealized inhibitor [52]; a similar saturation was shown for fluoromethanes, which trap $\mathrm{H}$-atoms non-catalytically [53]. Although $\mathrm{Fe}(\mathrm{CO})_{5}$ may have the confounding effect of condensation, the finding of catalytic cycle saturation has practical implications for fire suppressant design. For example, a blend of non-condensing chemical fire suppressants might be used to rapidly drop the radical mole fractions, but the performance of such a blend could be limited by catalytic cycle saturation. To produce effective blends, it may be advantageous to combine catalytic agents with those that lower the equilibrium mole fraction of radicals, either thermally or chemically [54].

To further explore the importance of the various reactions, we calculate firstorder sensitivity coefficients of the burning velocity to the reaction rates [33,55]. Figure 7 shows the sensitivity coefficients for the three different values of $\mathrm{X}_{\mathrm{O}_{2}, 0 \mathrm{x}}$ with $50 \mathrm{ppm}$ of $\mathrm{Fe}(\mathrm{CO})_{5}$. The calculations show that among the reactions in the iron mechanism, the reactions in the $\mathrm{O}$-atom and $\mathrm{H}$-atom catalytic cycles are most important for reducing burning velocity. As the oxygen concentration increases, the sensitivity coefficients of the reactions in the catalytic cycles decrease. 


\section{Effect of $\mathrm{H}_{2}$ mole fraction}

When $\mathrm{X}_{\mathrm{O}_{2}, 0 \mathrm{x}}$ is changed, the radical pool and flame temperature are affected. Since the inhibitor behavior is affected by both of these variables, it is desirable to change the radical pool without changing the temperature. In CO flames, this can be accomplished by varying $X_{\mathrm{H}_{2}}$. Within the limits set by our experimental apparatus, we were able to stabilize $\mathrm{CO}$ flames with $\mathrm{X}_{\mathrm{H}_{2}}$ of $0.002,0.005,0.01$, and 0.015 . An elevated oxygen content relative to air $\left(24 \% \mathrm{O}_{2} / 76 \% \mathrm{~N}_{2}\right)$ was necessary to achieve this range. Below $\mathrm{X}_{\mathrm{H}_{2}}=0.002$ the flame would not stabilize at a height of $13 \mathrm{~mm}$; above $\mathrm{X}_{\mathrm{H}_{2}}=0.015$ the flame oscillated too much for accurate measurement. Table 5 lists calculated maximum mole fraction and amount of superequilibrium for $\mathrm{O}, \mathrm{H}$, and $\mathrm{OH}$ for $\mathrm{CH}_{4}$-air and $\mathrm{CO}^{-} \mathrm{H}_{2}-\mathrm{O}_{2}-$ $\mathrm{N}_{2}$ flames with varying $\mathrm{X}_{\mathrm{H}_{2}}$. As the table shows, the variation of $\mathrm{X}_{\mathrm{H}_{2}}$ results in a change in maximum $\mathrm{H}$-atom and $\mathrm{OH}$ mole fraction of about a factor of 3.5 (approximately linearly with $\mathrm{X}_{\mathrm{H}_{2}}$ ), and little change in maximum O-atom mole fraction. Note also that the $\mathrm{O}$-atom superequilibrium is approximately constant with $\mathrm{X}_{\mathrm{H}_{2}}$, but that $\mathrm{H}$-atom and $\mathrm{OH}$ superequilibrium increases as $\mathrm{X}_{\mathrm{H}_{2}}$ increases.

Comparing the $\mathrm{CO}$ flames with a $\mathrm{CH}_{4}$ flame, several features stand out: 1) the maximum O-atom mole fraction is about four times higher in the $\mathrm{CO}$ flames, 2) the $\mathrm{H}$ atom mole fraction is lower in the $\mathrm{CO}$ flames (but is approaching the $\mathrm{CH}_{4}$ value as $\mathrm{X}_{\mathrm{H}_{2}}$ increases), 3) the maximum $\mathrm{OH}$ concentration is 3 to 8 times lower in the $\mathrm{CO}$ flames. These differences allow testing and study of the inhibition mechanism under significantly different flame conditions.

Figure 8 shows the effect of $\mathrm{Fe}(\mathrm{CO})_{5}$ on flames with different levels of $\mathrm{H}_{2}$ in the reactants and $\mathrm{X}_{\mathrm{O}_{2}, 0 \mathrm{x}}=0.24$. For reference, experimentally determined normalized burning velocities for $\mathrm{CH}_{4}$-air flames [7] are also shown. (The slight discontinuity in the $X_{H_{2}}=0.015$ data (' $x$ ' symbols) between $X_{\text {in }}=150$ and 250 ppm occurs because mass flow controllers with slightly different calibrations were used for the low $X_{\text {in }}$ and high $X_{\text {in }}$ measurements.) Compared to methane flames, the effect of small amounts of $\mathrm{Fe}(\mathrm{CO})_{5}$ in $\mathrm{CO}-\mathrm{H}_{2}$ flames is weaker for $\mathrm{X}_{\mathrm{H}_{2}}=0.01$ and 0.015 , about equal for $\mathrm{X}_{\mathrm{H}_{2}}=0.005$, and stronger for $X_{H_{2}}=0.002$ (note that the $X_{H_{2}}=0.002$ flame was not stable for $X_{\text {in }}>50$ ppm). A significant finding is that the $\mathrm{CH}_{4}$ curve shows linear behavior longer than the $\mathrm{CO}$ curves, resulting in a lower normalized burning velocity at high $\mathrm{Fe}(\mathrm{CO})_{5}$. This is surprising since the reduced effect at high $X_{\text {in }}$ is believed to be due primarily to condensation of iron species. One would expect less condensation in the $120 \mathrm{~K}$ hotter CO flames, and therefore a strong inhibition effect to higher $X_{\text {in }}$. The opposite behavior indicated in Figure 8 implies that saturation of the catalytic cycles may be the dominant cause for reduced effectiveness, or perhaps that the degree of iron-species condensation is increased in the slower CO flames.

Numerical calculations have been performed for the moist $\mathrm{CO}$ flames with varying $\mathrm{X}_{\mathrm{H}_{2}}$, and Figure 9 compares the calculations with measurements of normalized burning velocity. Similar to the predictions for varying $\mathrm{X}_{\mathrm{O}_{2,0 x}}$ (Figure 2 ), at low $\mathrm{Fe}(\mathrm{CO})_{5}$ mole fraction $(<100 \mathrm{ppm})$, the mechanism reasonably predicts the magnitude of 
inhibition and dependence on $\mathrm{X}_{\mathrm{H}_{2}}$ (although the predicted inhibition is too strong for higher values of $\mathrm{X}_{\mathrm{H}_{2}}$ ). In addition, the leveling off is not predicted and there is little difference between the calculations at different $\mathrm{X}_{\mathrm{H}_{2}}$, other than the varying initial slopes; that is, the point where diminishing effectiveness starts is not predicted by the mechanism.

Figure 10 presents the fractional $\mathrm{H}$ - and $\mathrm{O}$-atom destruction from the iron species catalytic cycles. The fractional amount of $\mathrm{O}$-atom scavenging is highest in flames with low $\mathrm{X}_{\mathrm{H}_{2}}$, explaining why the hydrogen deficient flames are inhibited more strongly at low $X_{\text {in }}$. For $X_{\text {in }}$ above $100 \mathrm{ppm}$, the fraction of $\mathrm{O}$-atoms consumed through the iron reactions is around 0.85 for $X_{H_{2}}=0.002$, but only 0.55 for $X_{H_{2}}=0.015$. Figure 10 shows (as does Figure 6), that the $\mathrm{O}$-atom cycle saturates at a lower $\mathrm{Fe}(\mathrm{CO})_{5}$ mole fraction than the $\mathrm{H}$-atom cycle. The importance of the $\mathrm{O}$-atom cycle in $\mathrm{CO}$ flames and its more complete saturation may be one of the reasons that the normalized burning velocity levels off at a higher value in the $\mathrm{CO}$ flames than the $\mathrm{CH}_{4}$ flame.

Sensitivity coefficients of the burning velocity to selected reaction rates were also calculated for flames with $50 \mathrm{ppm}$ of $\mathrm{Fe}(\mathrm{CO})_{5}$ and varying $\mathrm{X}_{\mathrm{H}_{2}}$. At low hydrogen content the $\mathrm{O}$-atom cycle reactions have the highest sensitivities, but as $\mathrm{X}_{\mathrm{H}_{2}}$ increases, their sensitivity coefficients decrease. As $\mathrm{X}_{\mathrm{H}_{2}}$ increases, the regeneration step $\left(\mathrm{FeO}+\mathrm{H}_{2} \mathrm{O}\right)$ in the $\mathrm{H}$-atom cycle becomes more important, while the other two reactions become less important.

We also measured normalized burning velocity for rich $(\phi=1.2)$ and lean $(\phi=0.8)$ $\mathrm{CO}-\mathrm{H}_{2}$ flames with $\mathrm{X}_{\mathrm{H}_{2}}=0.01$, and found that inhibition is slightly stronger for lean flames than for rich flames. As in the case of $\mathrm{CH}_{4}$ flames, the dependence on $\phi$ is weak.

\section{CONCLUSIONS}

In this paper we have presented measurements of the burning velocity of $\mathrm{CO}-\mathrm{H}_{2}-\mathrm{O}_{2}-\mathrm{N}_{2}$ flames with and without the inhibitor $\mathrm{Fe}(\mathrm{CO})_{5}$ over a range of initial $\mathrm{H}_{2}$ and $\mathrm{O}_{2}$ mole fractions. The inhibited flames had four different $\mathrm{H}_{2}$ concentrations, and three different $\mathrm{O}_{2}$ concentrations. A numerical model was used to simulate the flame inhibition using a gas-phase chemical mechanism. Based on the experiments and calculations, we find

1. For uninhibited flames, experimental burning velocities are within $10 \%$ of the results of calculations using the mechanism from Yetter et al. [36] for several different rates of the $\mathrm{CO}+\mathrm{OH} \leftrightarrow \mathrm{CO}_{2}+\mathrm{H}$ reaction. Use of the rate of $\mathrm{Yu}$ et al. [38] results in excellent agreement with our data, whereas use of the 1992 recommendation of Baulch et al. [39] results in predicted burning velocities that are significantly higher than the measurements.

2. For inhibited flames, the calculations and experiments show good qualitative agreement. The degree of quantitative agreement depends strongly on the rates of the $\mathrm{CO}+\mathrm{OH} \leftrightarrow \mathrm{CO}_{2} \mathrm{H}$ reaction, the reactions in the $\mathrm{H}$-atom cycle, and the $\mathrm{FeO}_{2}+\mathrm{O} \leftrightarrow \mathrm{FeO}+\mathrm{O}_{2}$ reaction. 
3. Most of the chemical inhibition occurs through a catalytic recombination cycle that converts $\mathrm{O}$ atoms into $\mathrm{O}_{2}$ molecules. This cycle was not found to be important in the previous numerical study of methane flames. The $\mathrm{H}$-atom cycle that caused most of the radical scavenging in the methane flames is also active in the $\mathrm{CO}$ flames described here, but is of secondary importance.

4. Reaction flux calculations show that when $X_{H_{2}}$ is varied, the fractional flux of $\mathrm{O}$ atom through key iron reactions is proportional to the experimentally measured degree of inhibition, while the fractional flux of $\mathrm{H}$ atom does not change appreciably. When $\mathrm{X}_{\mathrm{O}_{2}, 0 x}$ is varied, the fractional flux of $\mathrm{O}$ atom does not change appreciably, while the fractional flux of $\mathrm{H}$ atom is proportional to the experimentally measured degree of inhibition.

5. In the calculated results, the O-atom cycle saturates at a relatively low inhibitor mole fraction ( $100 \mathrm{ppm})$, while the $\mathrm{H}$-atom cycle saturates at a much higher inhibitor mole fraction ( $\sim 400 \mathrm{ppm})$. The earlier saturation of $\mathrm{O}$-atom cycle compared to the $\mathrm{H}$-atom cycle could be a reason why the $\mathrm{CO}$ flames have higher normalized burning velocity than $\mathrm{CH}_{4}$ flames at high $\mathrm{Fe}(\mathrm{CO})_{5}$ mole fraction.

6. Catalytic cycle saturation has practical implications for fire suppressant design. For

example, catalytic cycle saturation could limit the performance of a blend of chemical fire suppressants.

There are several practical implications for the suppression of hydrocarbon flames from the present work. Depending upon the hydrogen content of the fuel, the catalytic recombination of $\mathrm{O}$ atom may be as important as catalytic recombination of $\mathrm{H}$ atom and should be considered. Catalytically-acting agents may be useful only up to a certain mole fraction; above that value, additional agent may prove far less effective. Finally, if elimination of radical superequilibrium is readily achieved by a catalyticallyacting agent, further reduction in overall reaction rate may require additives which lower the equilibrium values of radicals, either thermally or chemically.

The inhibition mechanism qualitatively reproduces the dependence of flame inhibition on hydrogen and oxygen concentration at low inhibitor loading, but several questions remain unanswered. The most critical one is why the normalized burning velocity levels off as the $\mathrm{Fe}(\mathrm{CO})_{5}$ concentration increases. Results in the present paper imply that saturation of the catalytic cycles may be important. This suggestion is in addition to the strong arguments for the importance of condensation of active iron compounds in the flame presented in previous work. In light of the present results, there is an even greater need for measurements of particles in flames inhibited by $\mathrm{Fe}(\mathrm{CO})_{5}$ in order to understand the reason for the loss of effectiveness of this very powerful flame inhibitor. Of course, measurement of the rates of key iron reactions, especially the reactions in the catalytic cycles, is also an important area for future work.

We are grateful to undergraduate student researcher $\mathrm{N}$ ikki Prive for assistance with data 
acquisition and uncertainty analysis programs, and D r. Rich Y etter for discussion of the chemical kinetics of $\mathrm{CO}$ oxidation.

[1]. Lask, G. and Wagner, H.G., Eighth Symposium (International) on Combustion, Williams and Wilkins Co., Baltimore, 1962, pp. 432-438.

[2]. Miller, D.R., Evers, R.L., and Skinner, G.B., Combust. Flame 7:137 (1963).

[3]. Bulewicz, E.M. and Padley, P.J., Thirteenth Symposium (International) on Combustion, The Combustion Institute, Pittsburgh, 1971, pp. 73-80.

[4]. Bulewicz, E.M. and Padley, P.J., Chem. Phys. Lett. 9:467 (1971).

[5]. Vanpee, M. and Shirodkar, P., Seventeenth Symposium (International) on Combustion, The Combustion Institute, Pittsburgh, 1979, pp. 787-795.

[6]. Bonne, U., Jost, W., and Wagner, H.G., Fire Research A bstracts and Reviews 4:6 (1962).

[7]. Reinelt, D. and Linteris, G.T., Twenty-Sixth Symposium (International) on Combustion, The Combustion Institute, Pittsburgh, 1996, pp. 1421-1428.

[8]. Rumminger, M.D., Reinelt, D., Babushok, V., and Linteris, G.T., Combust. Flame 116:207 (1999).

[9]. Palmer, H.B. and Seery, D.J., Combust. Flame 4:213 (1960).

[10]. Safieh, H.Y., Vandooren, J., and Van Tiggelen, P.J., Nineteenth Symposium (International) on Combustion, The Combustion Institute, Pittsburgh, 1982, pp. 117.

[11]. Safieh, H.Y. and Van Tiggelen, P.J., Journal D e Chimie Physique 81:461 (1984).

[12]. da Cruz, F.N., Vandooren, J., and Van Tiggelen, P., Bull. Soc. Chim. Belg. 97:1011 (1988).

[13]. Vandooren, J., da Cruz, F.N., and Van Tiggelen, P.J., Twenty-Second Symposium (International) on Combustion, The Combustion Institute, Pittsburgh, PA, 1988, pp. 1587-1595.

[14]. Masri, A.R., Dally, B.B., Barlow, R.S., and Carter, C.D., Combust. Sci. Technol. 114:17 (1996).

[15]. Fallon, G.S., Chelliah, H.K., and Linteris, G.T., Twenty-Sixth Symposium (International) on Combustion, The Combustion Institute, Pittsburgh, 1996, pp. 1395-1403. 
[16]. Linteris, G.T., Combust. Flame 107:72 (1996).

[17]. Jensen, D.E. and Jones, G.A., J. Chem. Phys. 60:3421 (1974).

[18]. Wires, R., Watermeier, L.A., and Strehlow, R.A., J. Phys. Chem. $63: 989$ (1959).

[19]. Scholte, T.G. and Vaags, P.B., Combust. Flame 3:511 (1959).

[20]. Scholte, T.G. and Vaags, P.B., Combust. Flame 3:503 (1959).

[21]. Vagelopoulos, C.M. and Egolfopoulos, F.N., Twenty-Fifth Symposium (International) on Combustion, The Combustion Institute, Pittsburgh, PA, 1994, pp. 1317-1323.

[22]. Mache, H. and Hebra, A., Sitzungsber. Ö sterreich. A kad. W iss. Ila, 150:157 (1941).

[23]. Van Wonterghem, J. and Van Tiggelen, A., Bull. Soc. Chim. Belg. $63: 235$ (1954).

[24]. Andrews, G.E. and Bradley, D., Combust. Flame 18:133 (1972).

[25]. Linteris, G.T. and Truett, L., Combust. Flame 106:15 (1996).

[26]. Image Tool is a free Windows95-based program developed at the University of Texas Health Science Center at San Antonio, Texas and available from the Internet by anonymous FTP from ftp:// maxrad6.uthscsa.edu or http:/ / ddsdx.uthscsa.edu

[27]. Taylor, B. N. and Kuyatt, C. E., Guidelines for Evaluating and Expressing the Uncertainty of NIST M easurement Results, National Institute of Standards and Technology, NIST Technical N ote 1297, 1994.

[28]. Moffat, R.J., Transactions of the A SM E 104:250 (1982).

[29]. Sun, C.J., Sung, C.J., and Law, C.K., Twenty-Fifth Symposium (International) on Combustion, The Combustion Institute, Pittsburgh, 1994, pp. 1391-1398.

[30]. Weinberg, F. J., O ptics of Flames, Butterworth, London, 1963.

[31]. Dunn-Rankin, D. and Weinberg, F., Combust. Flame 113:303 (1998).

[32]. Gilbert, A.G. and Sulzmann, K.G.P., J. Electrochem. Soc. 121:832 (1974).

[33]. Kee, R. J., Grcar, J. F., Smooke, M. D., and Miller, J. A., A Fortran Computer Program for Modeling Steady Laminar Onedimensional Premixed Flames, Sandia National Laboratories Report, SAN D85-8240, 1991.

[34]. Kee, R. J., Rupley, F. M., and Miller, J. A., CHEM KIN-II: A Fortran Chemical 
Kinetics Package for the Analysis of Gas Phase Chemical Kinetics, Sandia National Laboratory, SAND89-8009B, 1989.

[35]. Kee, R. J., Dixon-Lewis, G., Warnatz, J., Coltrin, R. E., and Miller, J. A., A Fortran Computer Package for the Evaluation of Gas-Phase, Multicomponent Transport Properties, Sandia N ational Laboratory, SAND86-8246, 1986.

[36]. Yetter, R., Dryer, F.L., and Rabit, H., Combust. Sci. Technol. $79: 97$ (1991).

[37]. Baulch, D. L., Drysdale, D. D., Horne, D. G., and Lloyd, A. C., Evaluated Kinetic D ata for High Temperature Reactions, vol. 1 and 2, Butterworths, London, 1973.

[38]. Yu, C.-L., Wang, C., and Frenklach, M., Eastern States Section of the Combustion Institute, The Combustion Institute, 1990, pp. 20-1 to 20-4.

[39]. Baulch, D.L., Cobos, C.J., Cox, R.A., Esser, C., Frank, P., Just, T., Kerr, J.A., Pilling, M.J., Troe, J., Walker, R.W., and Warnatz, J., J. Phys. Chem. Ref. Data 21:411 (1992).

[40]. Wooldridge, M.S., Hanson, R.K., and Bowman, C.T., Twenty-Fifth Symposium (International) on Combustion, The Combustion Institute, Pittsburgh, PA, 1994, pp. 741-748.

[41]. Mallard, W. B., Westley, F., Herron, J. T., Hampson, R. F., and Frizzell, D. H., N IST Chemical Kinetics D atabase: Version 6.0, National Institute of Standards and Technology, Gaithersburg, MD, 1994.

[42]. Rollason, R.J. and Plane, J.M.C., 15th International Symposium on Gas Kinetics, Royal Society of Chemistry, 1998, pp.

[43]. Day, M.J., Stamp, D.V., Thompson, K., and Dixon-Lewis, G., Thirteenth Symposium (International) on Combustion, The Combustion Institute, Pittsburgh, 1971, pp. 705-712.

[44]. Westbrook, C.K., Combust. Sci. Technol. 23:191 (1980).

[45]. Kellogg, C.B. and Irikura, K.K., Journal of Physical Chemistry a 103:1150 (1999).

[46]. Kaufman, F., Proc. R. Soc. London, A A 247:123 (1958).

[47]. Frankiewicz, T.C., Williams, F.W., and Gann, R.G., J. Chem. Phys. 61:402 (1974).

[48]. Helmer, M. and Plane, J.M.C., J. Chem. Soc., Faraday Trans. 90:395 (1994).

[49]. A khamadov, U.S., Zaslonko, I.S., and Smirnov, V.N., Kinetics and Catalysis 29:251 (1988). 
[50]. Fontijn, A., Kurzius, S.C., and Houghton, J.J., Fourteenth Symposium (International) on Combustion, The Combustion Institute, Pittsburgh, 1973, pp. 167-174.

[51]. An Interactive, Graphics Postprocessor for Numerical Simulations of Chemical Kinetics, http:/ / www.nist.gov/ cstl/ div836/ xsenkplot

[52]. Babushok, V., Tsang, W., Linteris, G.T., and Reinelt, D., Combust. Flame 115:551 (1998).

[53]. Linteris, G. T., in Halon Replacements (A.W. Miziolek and W. Tsang, Ed.), ACS Symposium Series 611, American Chemical Society, Washington, DC, pp. 260274, 1995.

[54]. Linteris, G.T., Burgess, D.R., Babushok, V., Zachariah, M., Westmoreland, P., and Tsang, W., Combust. Flame 113:164 (1998).

[55]. Smooke, M.D., Rabitz, H., Reuven, Y., and Dryer, F.L., Combust. Sci. Technol. 59:295 (1988). 


\section{FIGURE AND TABLE CAPTIONS}

Figure 1: Comparison of measured and calculated burning velocities of stoichiometric $\mathrm{CO}-\mathrm{H}_{2}$-air flames with varying amounts of $\mathrm{H}_{2}$ and four different rates for $\mathrm{CO}+\mathrm{OH} \leftrightarrow \mathrm{CO}_{2}+\mathrm{H}$. Also shown are Palmer and Seery's measurements [9].

Figure 2: Measured and calculated inhibition effect of $\mathrm{Fe}(\mathrm{CO})_{5}$ for various $\mathrm{O}_{2}$ concentrations in stoichiometric CO- $\mathrm{H}_{2}-\mathrm{O}_{2}-\mathrm{N}_{2}$ flames with $\mathrm{X}_{\mathrm{H}_{2}}=0.01$.

Figure 3: Comparison of experimental data with calculated results using 4 mechanism variations: 2 rates for $\mathrm{CO}+\mathrm{OH} \leftrightarrow \mathrm{CO}_{2} \mathrm{H}$ and 2 rates for the catalytic $\mathrm{H}$-atom scavenging cycle. Dotted lines use the slower rates for the reactions in the $\mathrm{H}$ atom cycle; the solid lines, the faster rates. $\phi=1.0, X_{0_{2}, 0 x}=0.21, X_{H_{2}}=0.01$.

Figure 4: Schematic diagram of reaction pathways in $\mathrm{CO}-\mathrm{H}_{2}-\mathrm{O}_{2}-\mathrm{N}_{2}$ flames based on the gas-phase mechanism of Ref. [8]. Thicker arrows correspond to higher reaction flux. Reaction partners are listed next to each arrow.

Figure 5: Profiles of $\mathrm{O}$-atom mole fraction at different $\mathrm{Fe}(\mathrm{CO})_{5}$ concentrations. $\phi=1.0$, $X_{\mathrm{O}_{2}, \mathrm{X}}=0.21, \mathrm{X}_{\mathrm{H}_{2}}=0.01$. The equilibrium value of $\mathrm{X}_{\mathrm{O}}$ is 0.0014 for the uninhibited flame and 0.0011 for the inhibited flames.

Figure 6: Calculated fractional $\mathrm{H}$-atom and $\mathrm{O}$-atom flux through key iron reactions at $\mathrm{X}_{\mathrm{H}_{2}}=0.01$ and varying $\mathrm{O}_{2}$ concentrations.

Figure 7: First-order sensitivity coefficients of the burning velocity with respect to reaction rate for selected reactions at $X_{\text {in }}=50 \mathrm{ppm}$, normal ized by the peak value for all reactions at all flame locations (which corresponds to $\mathrm{CO}+\mathrm{OH} \leftrightarrow \mathrm{CO}_{2}+\mathrm{H}$ ).

Figure 8: Measured inhibition effect of $\mathrm{Fe}(\mathrm{CO})_{5}$ for various $\mathrm{H}_{2}$ mole fractions in $\mathrm{CO}^{-} \mathrm{H}_{2-}$ $\mathrm{O}_{2}-\mathrm{N}_{2}$ flames with $\phi=1.0$ and $\mathrm{X}_{0_{2,0 x}}=0.24$. For comparison, the normalized burning velocity profile for a $\phi=1.0, X_{0_{2}, 0 x}=0.24 \mathrm{CH}_{4}$-air flame [7] is also shown. The uninhibited burning velocities used for the normalizations are listed in the Table 3. Polynomial curve fits of the data are provided for clarity.

Figure 9: Calculated and measured normalized burning velocities for flames inhibited by $\mathrm{Fe}(\mathrm{CO})_{5}$ for various $\mathrm{H}_{2}$ concentrations. $\phi=1.0$ and $\mathrm{X}_{\mathrm{O}_{2,0}}=0.24$.

Figure 10: Calculated fractional $\mathrm{H}$-atom and $\mathrm{O}$-atom flux through iron reactions at $\mathrm{X}_{\mathrm{O}_{2}, \mathrm{x}}=0.24$ and varying $\mathrm{H}_{2}$ concentrations.

Table 1: Measured burning velocity of uninhibited stoichiometric $\mathrm{CO}-\mathrm{H}_{2}$-air flames with $\mathrm{H}_{2}$ content varied.

Table 2: Measured and calculated burning velocity of uninhibited stoichiometric CO$\mathrm{H}_{2}-\mathrm{O}_{2}-\mathrm{N}_{2}$ flames with varying oxygen content and varying hydrogen content.

Table 3: Comparison of the rates for $\mathrm{CO}+\mathrm{OH} \leftrightarrow \mathrm{CO}_{2}+\mathrm{H}$ used in Figure 1. The rate expression and the forward rate $k_{f}=A T^{b} \exp \left(-\left(E_{a}\right) / R T\right)$ at several temperatures are presented. Units for $\mathrm{k}$ are $\mathrm{cm}$, mole, $\mathrm{s}$. 
Table 4: Calculated maximum mole fraction and superequilibrium mole fraction of $O$, $\mathrm{H}$, and $\mathrm{OH}$, and maximum temperature for three different $\mathrm{X}_{\mathrm{O}_{2}, \mathrm{ox}}$ for the uninhibited flames of Figure 2.

Table 5: Calculated maximum $\mathrm{O}, \mathrm{H}$, and $\mathrm{OH}$ mole fraction and superequilibrium; maximum temperature; and calculated burning velocity for four different values of $\mathrm{X}_{\mathrm{H}_{2}}$. Also shown for comparison are the same parameters for a $\mathrm{CH}_{4}$ $\mathrm{O}_{2}-\mathrm{N}_{2}$ flame. $\left(\mathrm{X}_{\mathrm{O}_{2}, \mathrm{x}}=0.24\right.$ and $\phi=1$ for all flames shown.) 
Table 1: Measured burning velocity of uninhibited stoichiometric $\mathrm{CO}-\mathrm{H}_{2}$-air flames with $\mathrm{H}_{2}$ content varied.

\begin{tabular}{|c|c|c|c|c|c|}
\hline$X_{\mathrm{H}_{2}}$ & $\begin{array}{r}V_{0, \exp } \\
(\mathrm{cm} / \mathrm{s})\end{array}$ & $X_{\mathrm{H}_{2}}$ & $\begin{array}{r}V_{0, \exp } \\
(\mathrm{cm} / \mathrm{s})\end{array}$ & $\mathrm{X}_{\mathrm{H}_{2}}$ & $\begin{array}{r}V_{0, \exp } \\
(\mathrm{cm} / \mathrm{s})\end{array}$ \\
\hline 0.0024 & $22.5 \pm 0.8$ & 0.0050 & $29.8 \pm 0.8$ & 0.0091 & $38.0 \pm 1.1$ \\
\hline 0.0030 & $24.8 \pm 0.7$ & 0.0060 & $30.9 \pm 0.9$ & 0.0101 & $39.7 \pm 1.0$ \\
\hline 0.0033 & $25.7 \pm 0.7$ & 0.0061 & $32.1 \pm 0.8$ & 0.0101 & $39.1 \pm 1.1$ \\
\hline 0.0036 & $26.6 \pm 0.7$ & 0.0070 & $33.9 \pm 0.9$ & 0.0111 & $40.6 \pm 1.1$ \\
\hline 0.0039 & $27.3 \pm 0.7$ & 0.0091 & $38.0 \pm 1.1$ & 0.0111 & $40.7 \pm 1.2$ \\
\hline 0.0040 & $25.5 \pm 0.7$ & 0.0070 & $33.2 \pm 0.9$ & 0.0117 & $41.9 \pm 1.1$ \\
\hline 0.0040 & $26.9 \pm 0.7$ & 0.0080 & $36.1 \pm 1.0$ & 0.0118 & $42.6 \pm 1.2$ \\
\hline 0.0045 & $28.7 \pm 0.7$ & 0.0081 & $35.4 \pm 0.9$ & 0.0122 & $42.5 \pm 1.4$ \\
\hline 0.0050 & $28.4 \pm 0.8$ & 0.0091 & $37.3 \pm 1.0$ & 0.0132 & $43.7 \pm 1.4$ \\
\hline
\end{tabular}

Table 2: Measured and calculated burning velocity of uninhibited stoichiometric $\mathrm{CO}-\mathrm{H}_{2}-\mathrm{O}_{2}-\mathrm{N}_{2}$ flames with varying oxygen content and varying hydrogen content.

\begin{tabular}{lllc}
$\mathrm{X}_{\mathrm{O}_{2,0 x}}$ & $\mathrm{X}_{\mathrm{H}_{2}}$ & $\begin{array}{l}\mathrm{V}_{0, \text { exp }} \\
(\mathrm{cm} / \mathrm{s})\end{array}$ & $\begin{array}{l}\mathrm{V}_{\mathrm{o} \text {,num }} \\
(\mathrm{cm} / \mathrm{s})\end{array}$ \\
\hline 0.183 & 0.01 & $32.7 \pm 0.8$ & 30.5 \\
0.21 & 0.01 & $39.6 \pm 1.1$ & 35.8 \\
0.24 & 0.002 & $25.1 \pm 0.6$ & 22.3 \\
0.24 & 0.005 & $36.2 \pm 0.9$ & 31.2 \\
0.24 & 0.01 & $46.2 \pm 1.4$ & 41.1 \\
0.24 & 0.015 & $59.0 \pm 2.4$ & 48.7
\end{tabular}


Table 3: Comparison of the rates for $\mathrm{CO}+\mathrm{OH} \leftrightarrow \mathrm{CO}_{2}+\mathrm{H}$ used in Figure 1. The rate expression and the forward rate $k_{f}=A T^{b} \exp \left(-\left(E_{a}\right) / R T\right)$ at several temperatures are presented. Units for $\mathrm{k}$ are $\mathrm{cm}$, mole, $\mathrm{s}$.

\begin{tabular}{c|ccc|ccc}
\multicolumn{1}{c}{} & \multicolumn{2}{c}{$\mathrm{Kf}_{\mathrm{f}}$} \\
\cline { 5 - 7 } & $\mathrm{A}$ & $\mathrm{b}$ & $\mathrm{E}_{\mathrm{a}} / \mathrm{R}$ & 1000 & 1500 & 2000 \\
\hline Baulch et al. (1973) [37] & $1.50 \mathrm{E}+07$ & 1.3 & -385 & $1.75 \mathrm{E}+11$ & $2.61 \mathrm{E}+11$ & $3.56 \mathrm{E}+11$ \\
Baulch et al. (1992) [39] & $3.25 \mathrm{E}+10$ & 1.5 & -250 & $2.57 \mathrm{E}+11$ & $4.34 \mathrm{E}+11$ & $6.41 \mathrm{E}+11$ \\
Wooldridge et al. [40] & $2.12 \mathrm{E}+12$ & 0 & 2630 & $1.53 \mathrm{E}+11$ & $3.67 \mathrm{E}+11$ & $5.69 \mathrm{E}+11$ \\
Yu et al. [38] & $4.4 \mathrm{E}+06$ & 1.547 & 67 & $1.89 \mathrm{E}+11$ & $3.56 \mathrm{E}+11$ & $5.58 \mathrm{E}+11$
\end{tabular}

Table 4: Calculated maximum mole fraction and superequilibrium mole fraction of $\mathrm{O}, \mathrm{H}$, and $\mathrm{OH}$, and maximum temperature for three different $\mathrm{X}_{\mathrm{O}_{2}, \mathrm{ox}}$ for the uninhibited flames of Figure 2.

\begin{tabular}{l|lll|}
\multirow{2}{*}{} & \multicolumn{3}{|c|}{$\mathrm{X}_{\mathrm{O}_{2}, \mathrm{Ox}}$} \\
\cline { 2 - 4 } & 0.183 & 0.21 & 0.24 \\
\hline $\mathrm{X}_{\mathrm{O}, \max }$ & 0.011 & 0.014 & 0.018 \\
$\mathrm{X}_{\mathrm{H}, \max }$ & 0.0045 & 0.0052 & 0.0058 \\
$\mathrm{X}_{\mathrm{OH}, \max }$ & 0.0024 & 0.0029 & 0.0035 \\
$\mathrm{X}_{\mathrm{O}, \max }-\mathrm{X}_{\mathrm{O}, \mathrm{eq}}$ & 0.01 & 0.013 & 0.015 \\
$\mathrm{X}_{\mathrm{H}, \max }-\mathrm{X}_{\mathrm{H}, \mathrm{eq}}$ & 0.0043 & 0.0049 & 0.0054 \\
$\mathrm{X}_{\mathrm{OH}, \max }-\mathrm{X}_{\mathrm{OH}, \text { eq }}$ & 0.00097 & 0.00095 & 0.00084 \\
$\mathrm{~T}_{\max }(\mathrm{K})$ & 2262 & 2376 & 2471
\end{tabular}


Table 5: Calculated maximum $\mathrm{O}, \mathrm{H}$, and $\mathrm{OH}$ mole fraction and superequilibrium; maximum temperature; and calculated burning velocity for four different values of $\mathrm{X}_{\mathrm{H}_{2}}$. Also shown for comparison are the same parameters for a $\mathrm{CH}_{4}-\mathrm{O}_{2}-\mathrm{N}_{2}$ flame. $\left(X_{0_{2}, 0 x}=0.24\right.$ and $\phi=1$ for all flames shown.)

\begin{tabular}{l|llll|l}
\cline { 2 - 5 } \multicolumn{1}{c|}{} & \multicolumn{4}{|c|}{$\mathrm{X}_{\mathrm{H}_{2}}$} \\
\cline { 2 - 5 } & 0.002 & 0.005 & 0.01 & 0.015 & $\mathrm{CH}_{4}$ \\
\hline $\mathrm{X}_{\mathrm{O}, \text { max }}$ & 0.018 & 0.018 & 0.018 & 0.017 & 0.0044 \\
$\mathrm{X}_{\mathrm{H} \text {,max }}$ & 0.002 & 0.0037 & 0.0058 & 0.0074 & 0.0085 \\
$\mathrm{X}_{\mathrm{OH}, \text { max }}$ & 0.0014 & 0.0024 & 0.0035 & 0.0044 & 0.011 \\
$\mathrm{X}_{\mathrm{O} \text {,max }}-\mathrm{X}_{\mathrm{O}, \text { eq }}$ & 0.016 & 0.016 & 0.015 & 0.015 & 0.0037 \\
$\mathrm{X}_{\mathrm{H}, \text { max }}-\mathrm{X}_{\mathrm{H}, \mathrm{eq}}$ & 0.0018 & 0.0034 & 0.0054 & 0.0068 & 0.0076 \\
$\mathrm{X}_{\mathrm{OH}, \text { max }}-\mathrm{X}_{\mathrm{OH}, \text { eq }}$ & 0.00024 & 0.0005 & 0.00084 & 0.00111 & 0.0049 \\
$\mathrm{~T}_{\max }(\mathrm{K})$ & 2471 & 2468 & 2471 & 2475 & 2353 \\
$\mathrm{~V}_{\text {o, num }}(\mathrm{cm} / \mathrm{s})$ & 22.3 & 31.2 & 41.1 & 48.7 & 55.6
\end{tabular}




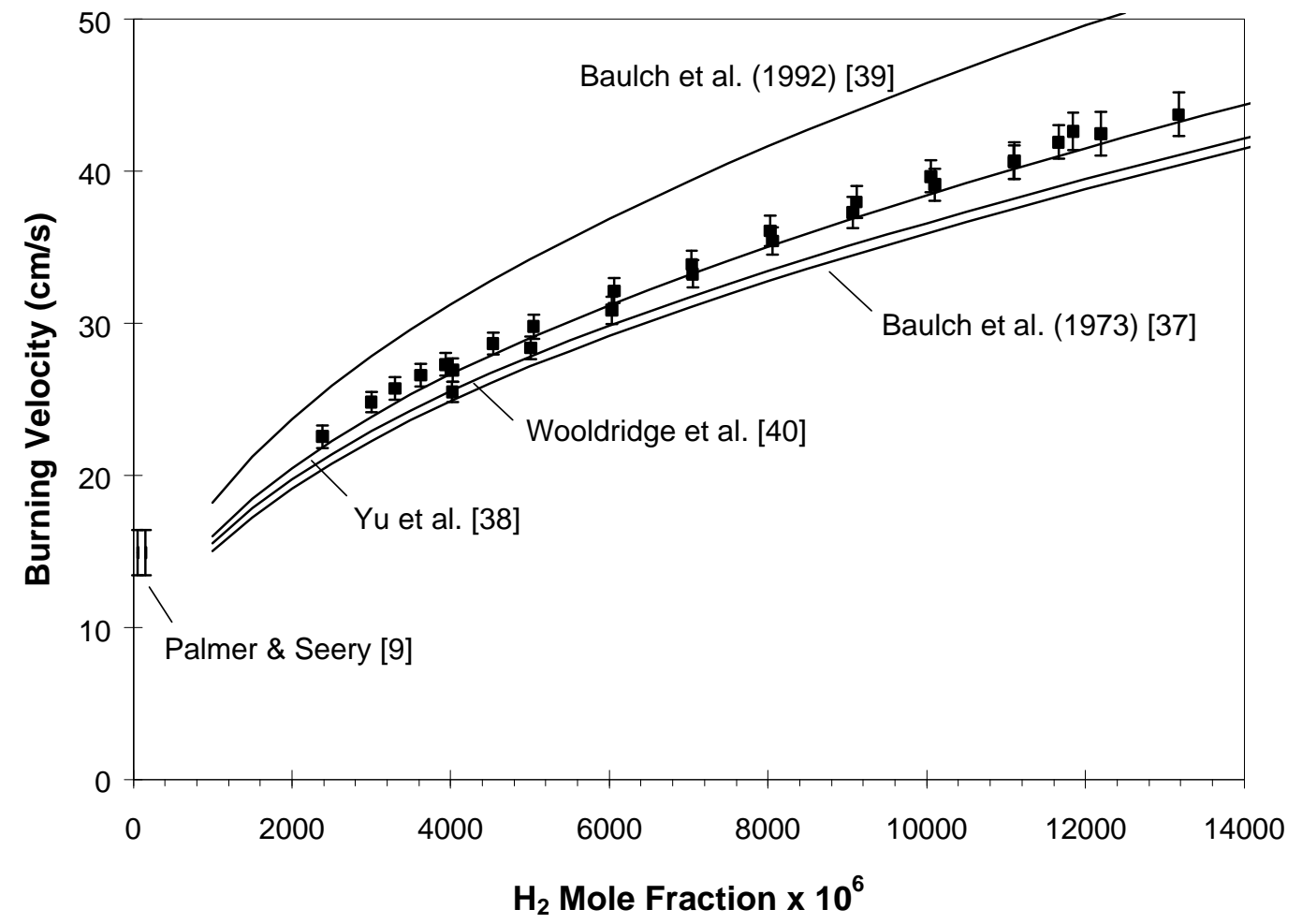

Figure 1: Comparison of measured and calculated burning velocities of stoichiometric $\mathrm{CO}-\mathrm{H}_{2}$-air flames with varying amounts of $\mathrm{H}_{2}$ and four different rates for $\mathrm{CO}+\mathrm{OH} \leftrightarrow \mathrm{CO}_{2}+\mathrm{H}$. Also shown are Palmer and Seery's measurements [9]. 


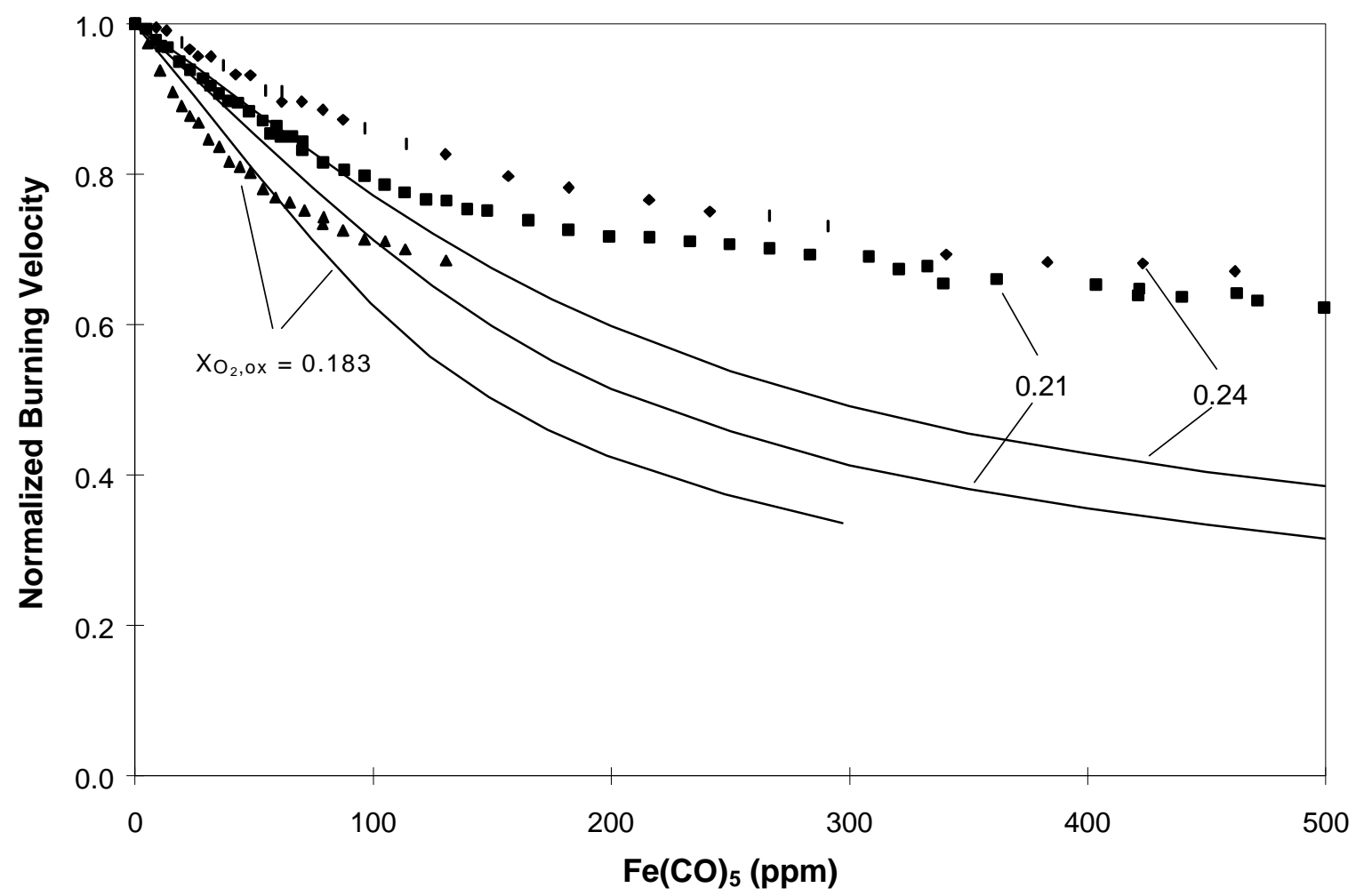

Figure 2: $M$ easured and calculated inhibition effect of $\mathrm{Fe}(\mathrm{CO})_{5}$ for various $\mathrm{O}_{2}$ concentrations in stoichiometric $\mathrm{CO}-\mathrm{H}_{2}-\mathrm{O}_{2}-\mathrm{N}_{2}$ flames with $\mathrm{X}_{\mathrm{H}_{2}}=0.01$. 


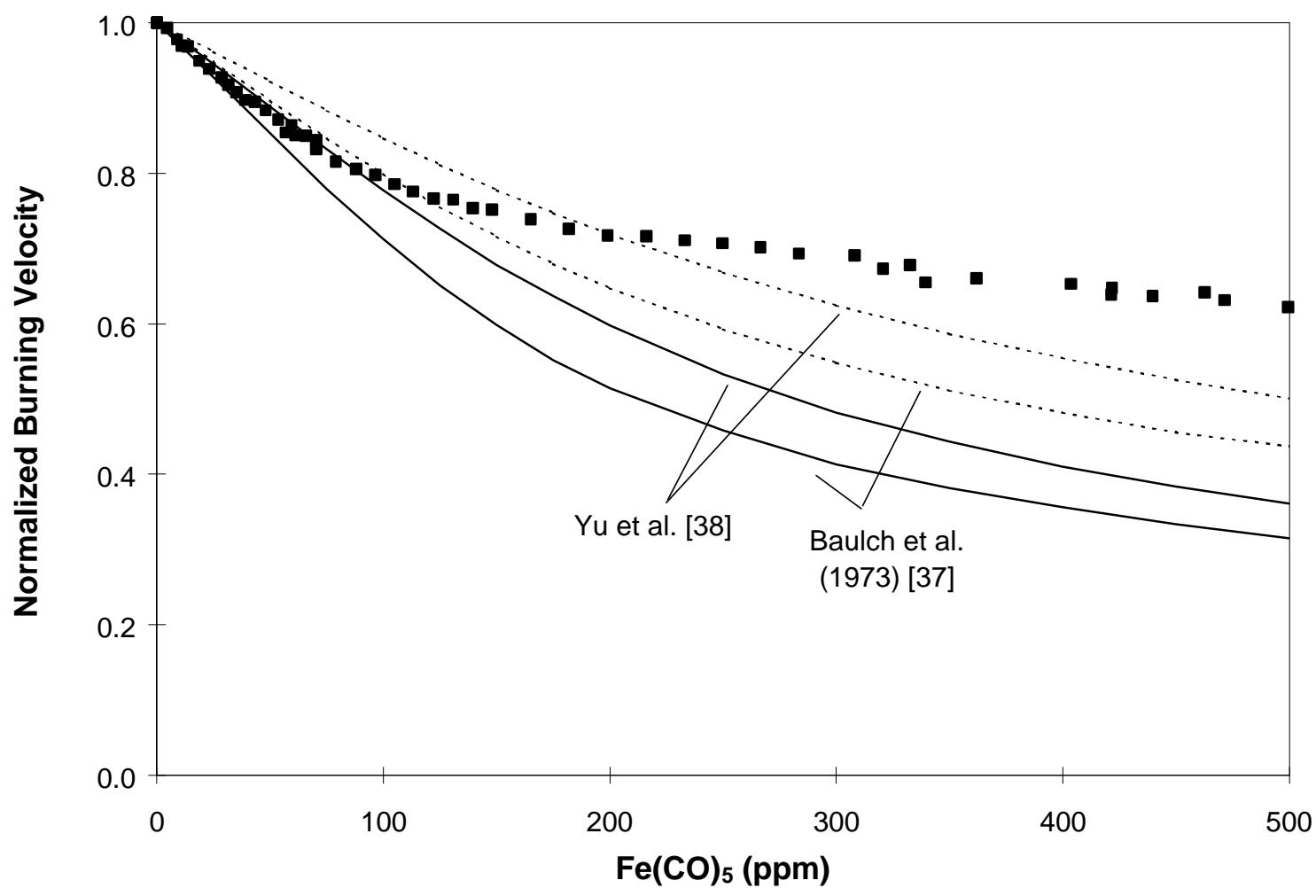

Figure 3: Comparison of experimental data with calculated results using 4 mechanism variations: 2 rates for $\mathrm{CO}+\mathrm{OH} \leftrightarrow \mathrm{CO}_{2}+\mathrm{H}$ and 2 rates for the catalytic $\mathrm{H}$ atom scavenging cycle. Dotted lines use the slower rates for the reactions in the $\mathrm{H}$ atom cycle; the solid lines, the faster rates. $\phi=1.0, \mathrm{X}_{\mathrm{O}_{2}, \mathrm{x}}=0.21, \mathrm{X}_{\mathrm{H}_{2}}=0.01$. 


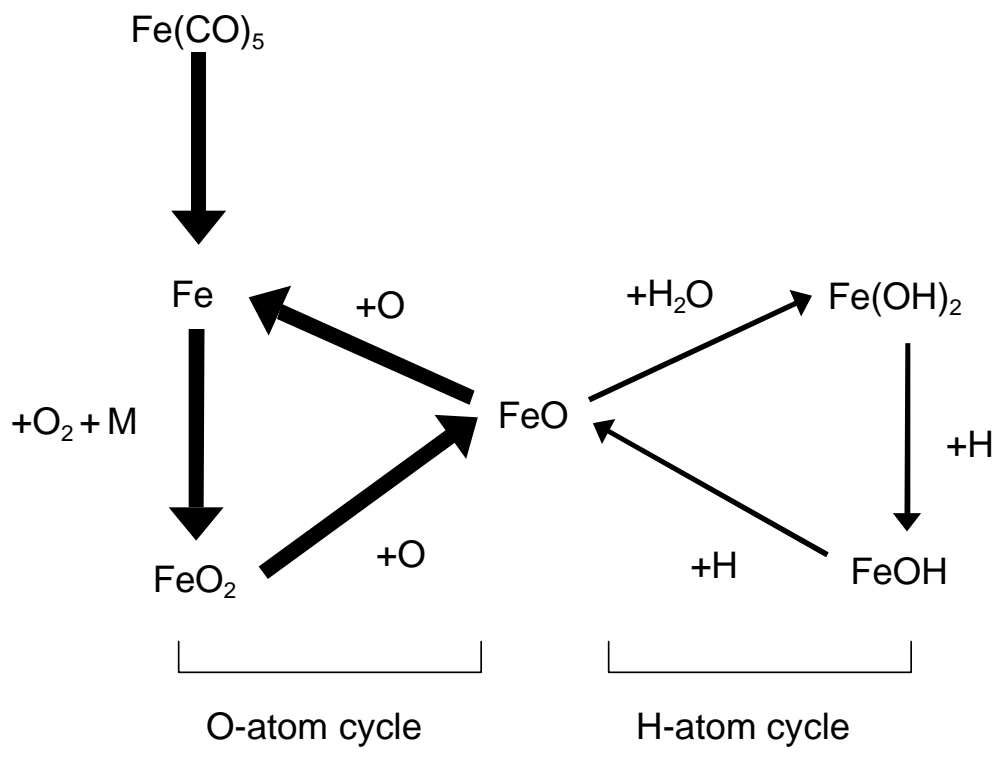

Figure 4: Schematic diagram of reaction pathways in $\mathrm{CO}-\mathrm{H}_{2}-\mathrm{O}_{2}-\mathrm{N}_{2}$ flames based on the gas-phase mechanism of Ref. [8]. Thicker arrows correspond to higher reaction flux. Reaction partners are listed next to each arrow. 


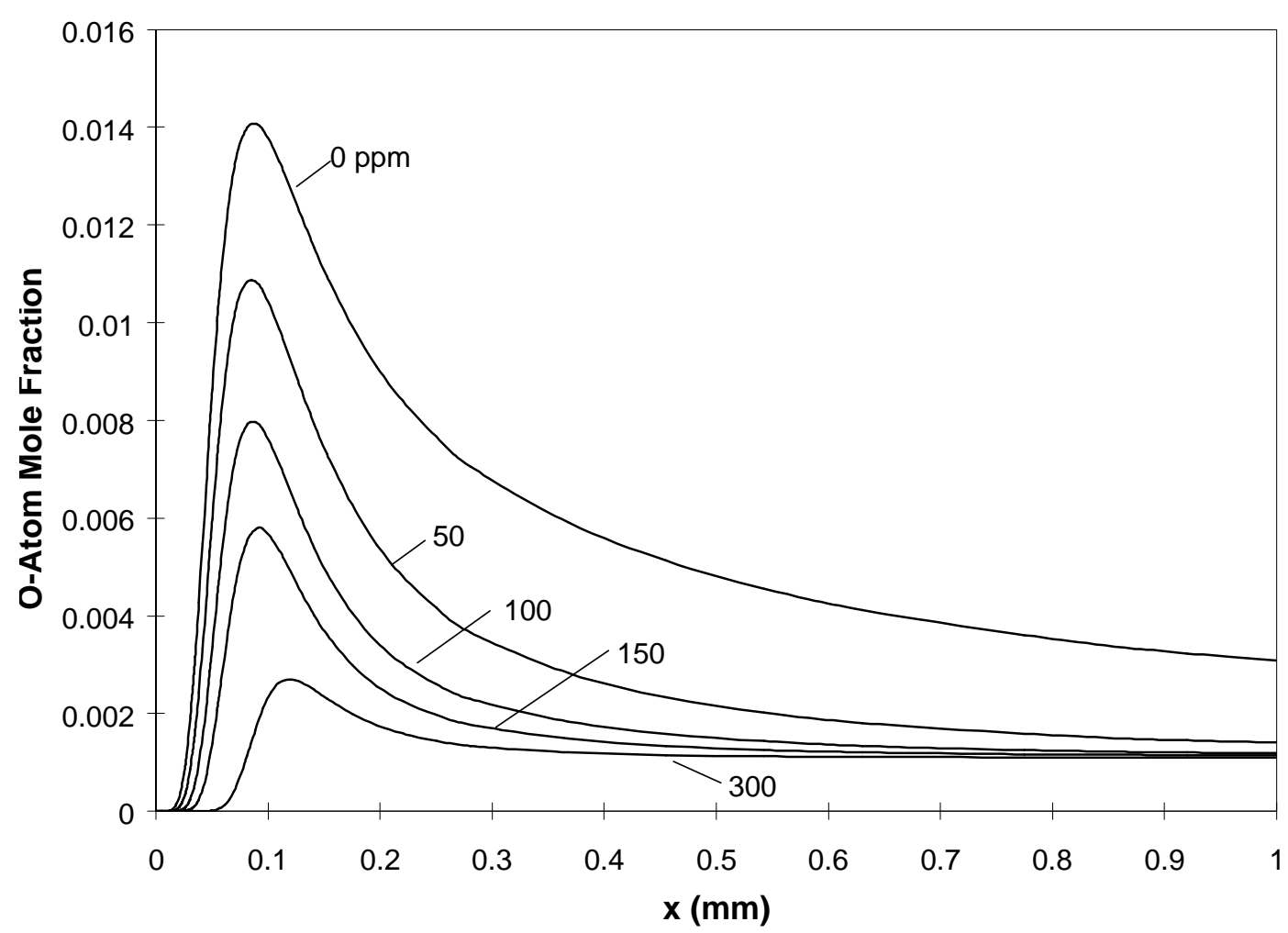

Figure 5: Profiles of 0 -atom mole fraction at different $\mathrm{Fe}(\mathrm{CO})_{5}$ concentrations. $\phi=1.0$, $X_{0_{2}, 0 x}=0.21, X_{H_{2}}=0.01$. The equilibrium value of $X_{0}$ is 0.0014 for the uninhibited flame and 0.0011 for the inhibited flames. 


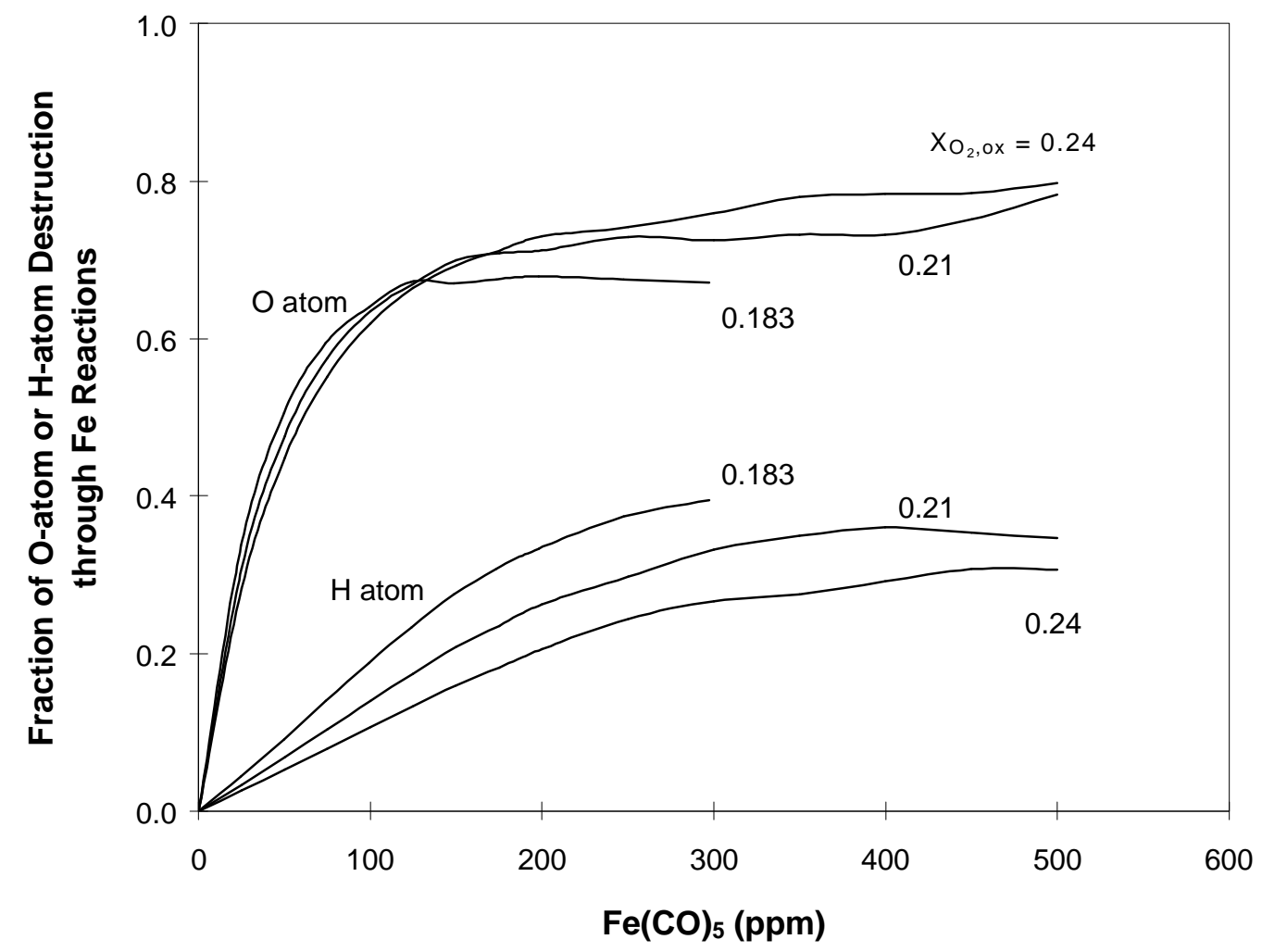

Figure 6: Calculated fractional $\mathrm{H}$-atom and $\mathrm{O}$-atom flux through key iron reactions at $X_{\mathrm{H}_{2}}=0.01$ and varying $\mathrm{O}_{2}$ concentrations. 


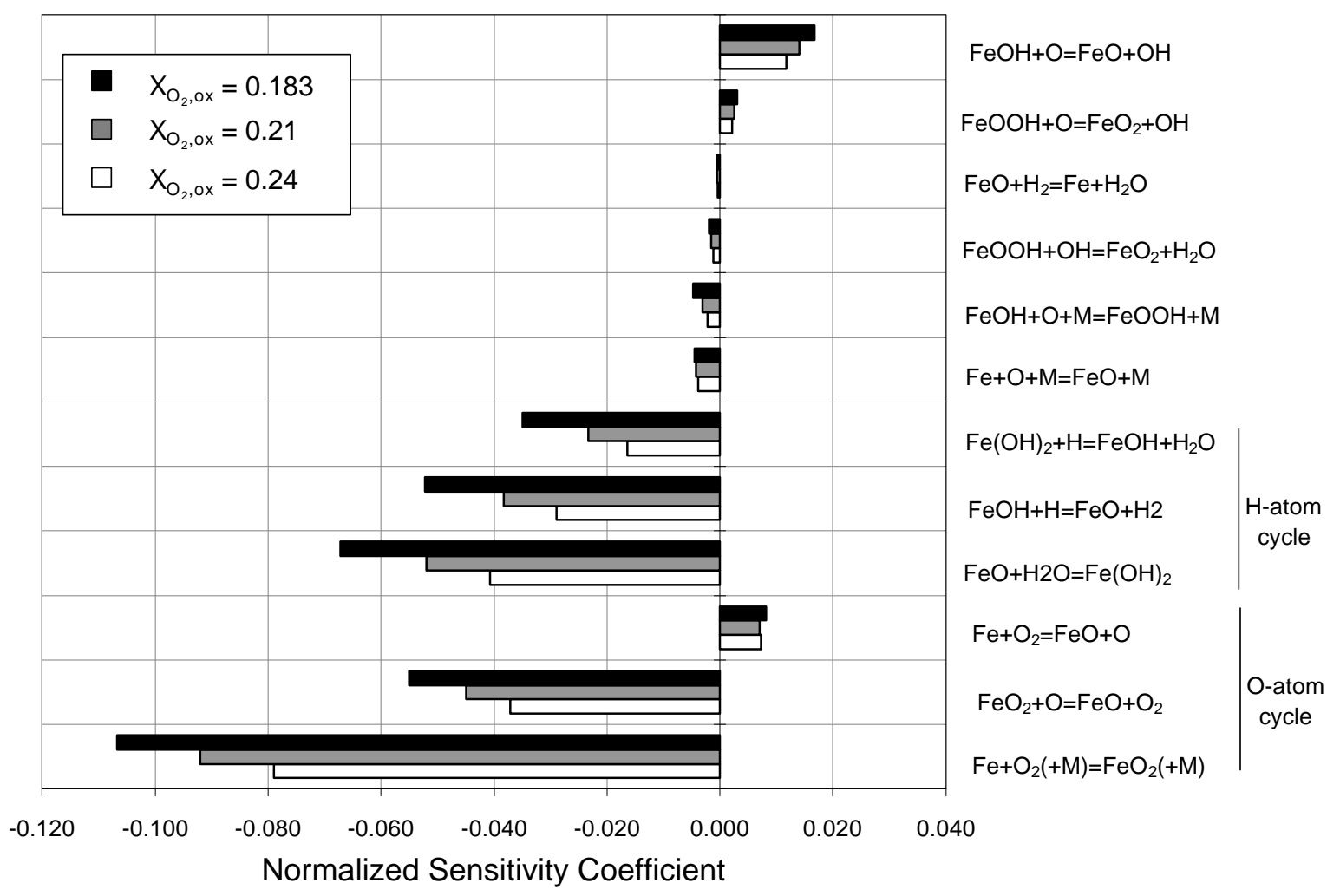

Figure 7: First-order sensitivity coefficients of the burning velocity with respect to reaction rate for selected reactions at $X_{\text {in }}=50 \mathrm{ppm}$, normalized by the peak value for all reactions at all flame locations (which corresponds to $\mathrm{CO}+\mathrm{OH} \leftrightarrow \mathrm{CO}_{2}+\mathrm{H}$ ). 


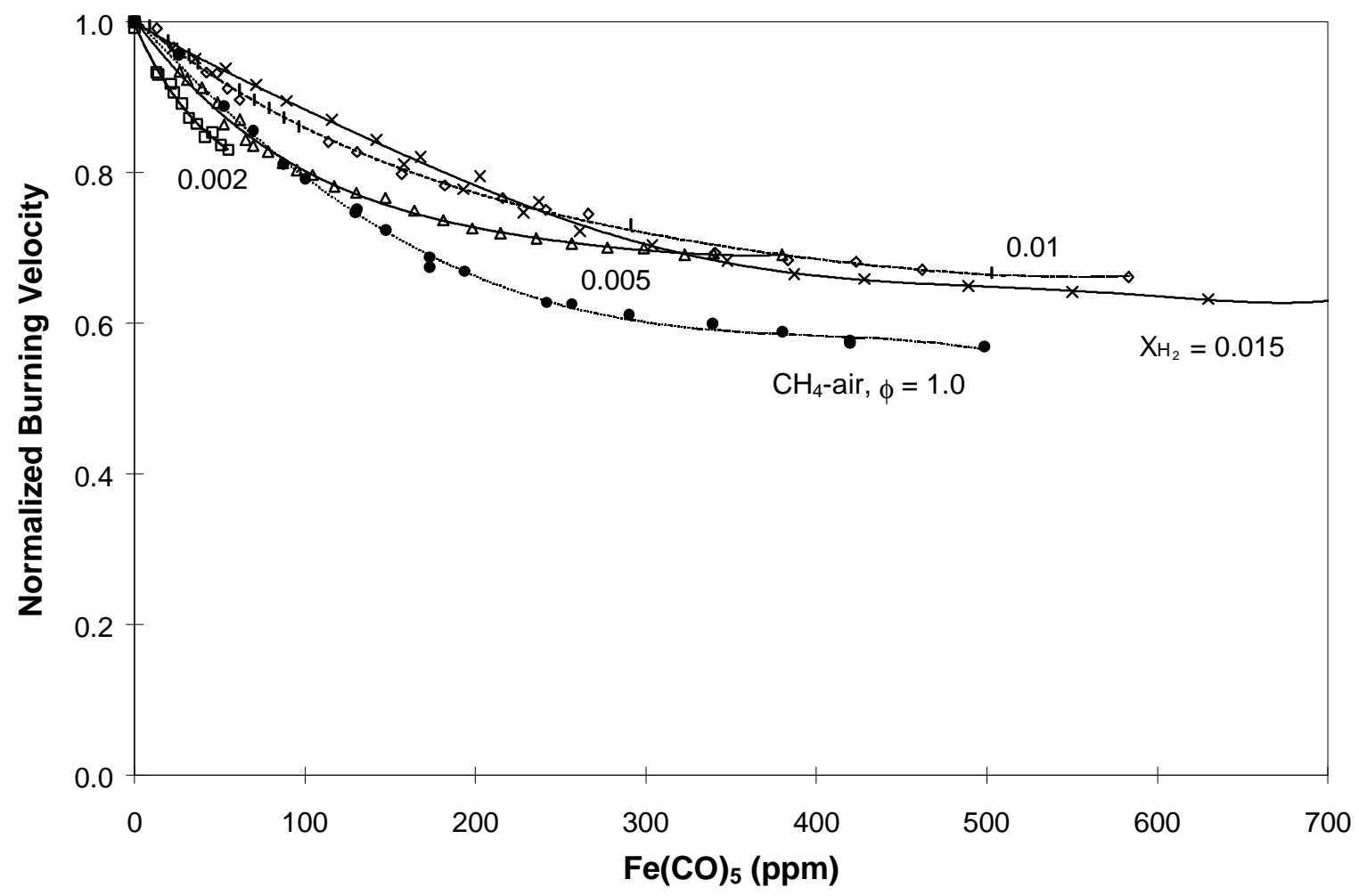

Figure 8: M easured inhibition effect of $\mathrm{Fe}(\mathrm{CO})_{5}$ for various $\mathrm{H}_{2}$ mole fractions in $\mathrm{CO}$ $\mathrm{H}_{2}-\mathrm{O}_{2}-\mathrm{N}_{2}$ flames with $\phi=1.0$ and $X_{0_{2}, 0 x}=0.24$. For comparison, the normalized burning velocity profile for a $\phi=1.0, X_{0_{2}, 0 x}=0.24 \mathrm{CH}_{4}$-air flame [7] is also shown. The uninhibited burning velocities used for the normalizations are listed in the Table 2. Polynomial curve fits of the data are provided for clarity. 


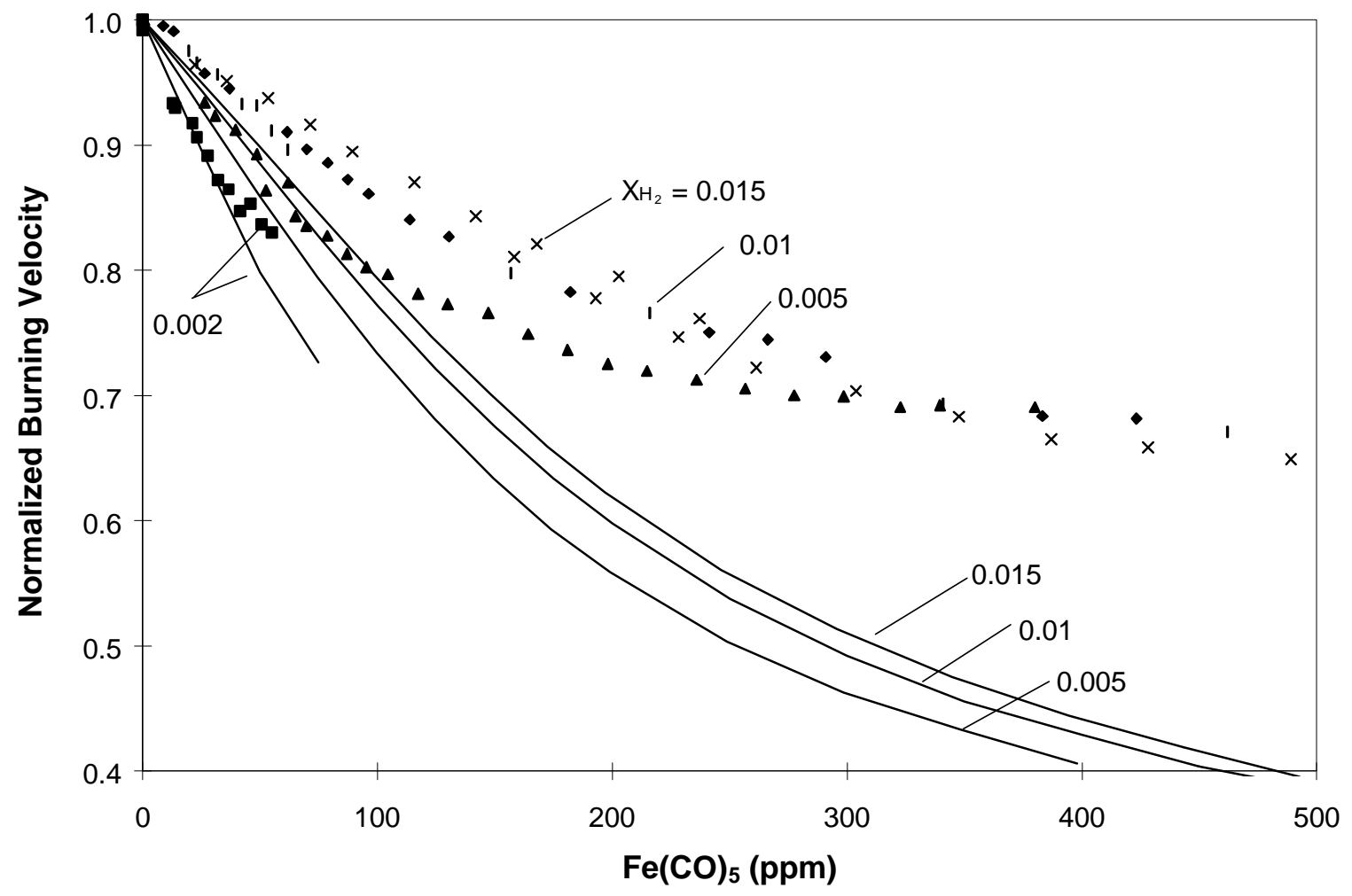

Figure 9: Calculated and measured normalized burning velocities for flames inhibited by $\mathrm{Fe}(\mathrm{CO})_{5}$ for various $\mathrm{H}_{2}$ concentrations. $\phi=1.0$ and $\mathrm{X}_{\mathrm{o}_{2,0 \mathrm{x}}}=0.24$. 


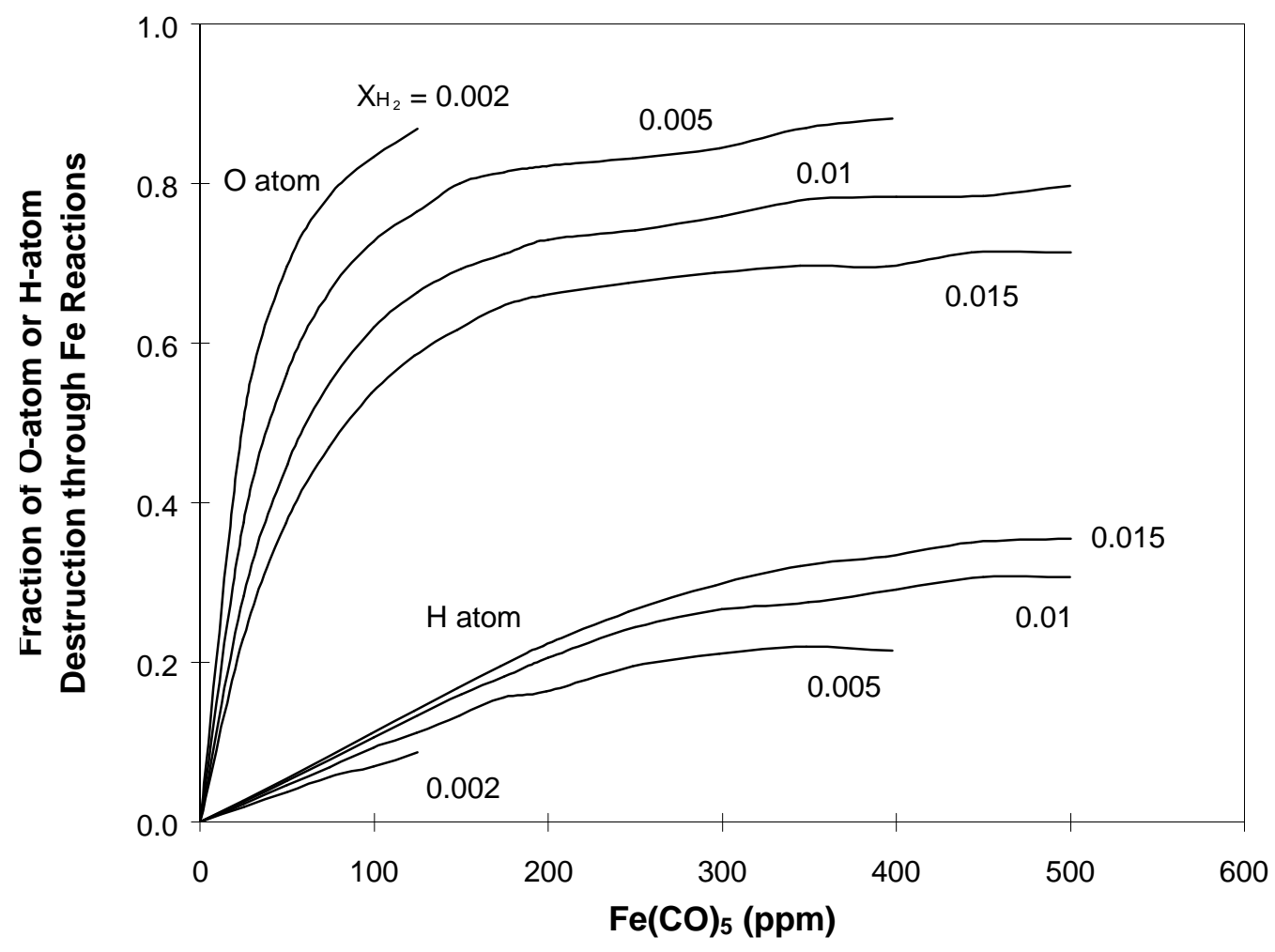

Figure 10: Calculated fractional $\mathrm{H}$-atom and $\mathrm{O}$-atom flux through iron reactions at $\mathrm{X}_{\mathrm{O}_{2}, \mathrm{ox}}=0.24$ and varying $\mathrm{H}_{2}$ concentrations. 